NIST

PUBLICATIONS

\section{Stopping Power of Fast Charged Particles in Heavy Elements}

\section{Hans Bichsel}

1211 22nd Avenue East

Seattle, Washington 98112-3534

U.S. DEPARTMENT OF COMMERCE Robert A. Mosbacher, Secretary NATIONAL INSTITUTE OF STANDARDS AND TECHNOLOGY

John W. Lyons, Director

QC

100

.456

\#4550

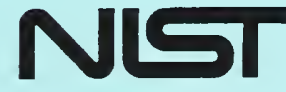

1991

C. 2 
NATIONAL INSTTTUTE OF STANDARDS \&

TECHNOLOGY

Research Information Center

Gaithersburg, MD 20899 


\section{Stopping Power of Fast Charged Particles in Heavy Elements}

\section{Hans Bichsel}

1211 22nd Avenue East

Seattle, Washington 98112-3534

April 1991

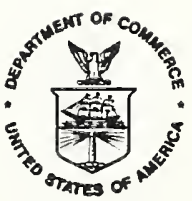

U.S. DEPARTMENT OF COMMERCE Robert A. Mosbacher, Secretary NATIONAL INSTITUTE OF STANDARDS AND TECHNOLOGY

John W. Lyons, Director 



\title{
Stopping Power of Fast Charged Particles in Heavy Elements
}

\author{
Hans Bichsel \\ 1211 22nd Avenue East \\ Seattle, Washington 98112-3534
}

2 September 1990

The stopping power formula from Bethe's theory contains terms which are known only approximately and must be estimated with the use of experimental data. These terms include a material constant, the mean excitation energy of the medium, and the shell-, Bloch-and Barkas-corrections. In an analysis of measured proton and alpha-particle stopping powers and ranges, modifying parameters have been introduced into these corrections, and the mean excitation energy was simultaneously adjusted, so as to get the closest possible agreement with experimental results. Such an analysis is reported here for elements with atomic numbers $Z \geq 57$. The modification parameters introduced for the shell corrections have a simple relation to atomic energy levels. The Bethe theory with the adopted mean excitation energies and proposed adjustments of the shell-and Barkas-corrections predicts stopping powers that are in close agreement with experimental values, within the experimental uncertainties. This agreement was obtained for protons with kinetic energies above about $0.5 \mathrm{MeV}$, and for heavier ions of charge $z$ at energies above $(z-1.5) \mathrm{MeV} / \mathrm{u}$.

Report of work done under contract for the National Institute of Standards and Technology 



\section{INTRODUCTION}

The Bethe-Bloch theory of stopping power, $S$, (Bethe, 1930; Bloch, 1933; Fano, 1963) with a Barkas effect correction term and including shell corrections has been shown to agree well with experimental data for protons and alpha particles with kinetic energies $T / M$ ( $M$ is the number of nucleons in the particle) above $0.5 \mathrm{MeV}$ traversing light elements for which Ivalues had been determined independently. A single free parameter for the Barkas effect was introduced (Bichsel and Porter, 1982). For heavier elements, semiempirical I-values and shell corrections were used to calculate $S$ for comparison with experimental data (e.g. Bichsel, 1961; Bichsel, 1972; Janni, 1982; Porter and Bryan, 1984; ICRU, 1984). Since shell corrections for the M-shells (Bichsel, 1983) and the separate L-subshells (B1chsel, 1987) are now avallable, I have explored the validity of the theory with these functions. It was necessary to introduce corrections for the outer (N, $O, P, Q)$ shells: they were derived from the M-shell corrections with a scaling procedure using atomic structure data. For all elements with $57 \leq Z \leq 92$, the I-value was the only free parameter not simply related to $\mathrm{Z}$. The theoretical Bloch function $I_{2}$ and an empirical function $L_{1}$ for the Barkas effect (Bichsel, 1990) were used.

The present study is an outgrowth of earlier work (Bichsel, 1961, 1964, 1967) and is an effort complementary to those by Andersen and Zlegler (1977), Zlegler (1977) and Janni (1982). Many observations about problems with experimental data were made in these references and should be studied there.

\section{THEORY}

The theory of $S$ for heavy elements is complex (see Table $X I$ below). It is not possible to calculate $S$ a priori with an

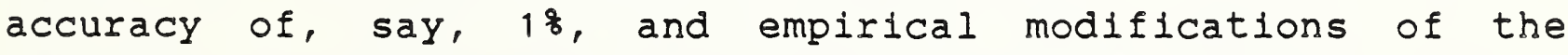
current a priori theoretical functions are needed to get calculated values $S_{t}$ agreeing with experimental data $S_{x}$. These modifications are attained by varying the values of parameters in the functions. Many of the parameters are quite interdependent: a change in a parameter causing an increase 
in $S$ over an extended energy range can readily be compensated by a change in one of the other parameters causing a decrease in $S$ (see Table IV below).

It is the purpose of the present paper to consider the complete theory of $S$ outlined below, and parameters used should have values plausibly related to atomic data. In other analyses, incomplete theories (e.g Janni, 1982, did not explicitly use $z^{3}$ and $z^{4}$ corrections) or polynomial fits to the shell corrections (where the parameters have no physical significance) were used (Andersen and Ziegler, 1977). The same goal is achieved with all these approaches: semiempirical functions are given which approximate the experimental data.

Further improvements in the theory of interactions of charged particles with matter have been achieved for collision cross sections (e.g. Anholt, 1979, Cohen and Harrigan, 1985), but similar improvements have not been made for the stopping power. Relativistic corrections for atomic properties are discussed in the Appendix, but were not used in the data analysis

\section{A. Stopping power, S.}

The expression used for the calculation of the stopping power of fast charged particles is

$S=-\frac{d T}{d x}=\frac{k}{\beta^{2}} \frac{z}{A} z^{2} L$

with $\mathrm{T}$ the kinetic energy ( $\mathrm{MeV})$ of the particle, $x$ the absorber thickness, $9 / \mathrm{cm}^{2}$, $\mathrm{k}=4 \pi \mathrm{e}^{4} \mathrm{~N}_{\mathrm{o}} / \mathrm{mc}^{2}=4 \pi \mathrm{r}^{2} \mathrm{~N}_{0} \mathrm{mc}^{2}=0.307072 \mathrm{MeV} \mathrm{cm}{ }^{2}$. $v_{2}=\beta c$ the speed of the incident particle, $\gamma^{2}=1 /\left(1-\beta^{2}\right), \quad \gamma=1+T / M_{0} c^{2}$,

ze the charge of the incident particle,

e the electron charge,

$m$ the electron rest-mass, $m c^{2}=511,000 \mathrm{ev}$,

$c$ the speed of light,

$r_{0}=2.817941 \cdot 10^{-13} \mathrm{~cm}$ the classical electron radius,

$\mathrm{N}_{0}^{\circ}=6.022045 \cdot 10^{23}$ atoms/mole, Avogadro's number, 
$\mathrm{Z}$ the atomic number of the absorber,

A the atomic weight of the absorber (in $g$ ),

I the stopping number ( $B$ in older papers), and

$M_{0}$ the rest mass of the particle; $p: M_{0} c_{2}^{2}=938.2561 \mathrm{MeV}$

$\alpha: M_{0} c^{2}=3727.316 \mathrm{MeV}$

Either $\beta$ or $T$ will be used as the variable indicating the particle energy, with $\beta^{2}=\left(T / M_{0} c^{2}\right) \cdot\left(2+T / M_{0} C^{2}\right) /\left(1+T / M_{0} C^{2}\right)^{2}$.

For particles heavier than electrons, the stopping number I is expressed in the form

$$
L(z)=I_{0}+z L_{1}+I_{2}(z)
$$

with

$$
I_{0}(\beta)=f(\beta)-\ln I-\frac{C(\beta)}{z}+(G(z, \beta)-\delta(\beta)) / 2
$$

where $f(\beta)=\ln \left(2 m c^{2} \beta^{2} \gamma^{2}\right)-\beta^{2}$, I is the mean excitation energy of the absorber, $C(\beta)$ the total shell correction, $G(z, \beta)$ the Mott correction term, $\delta$ the correction for the density effect, $L_{1}$ the Barkas correction term and $L_{2}$ the Bloch correction term. It is useful to define the experimental value of the stopping number, $I_{x}$ obtained by solving Eq.

for an experimental value $\mathrm{S}_{\mathrm{x}}$ of the stopping power:

$$
L_{x}(\beta)=S_{x}(\beta) \cdot A \beta^{2} /\left(k z^{2} z\right) \text {. }
$$

B. I-values.

The mean excitation energy I is defined by

$$
\begin{aligned}
\ln I= & \int_{0}^{\infty} f(E, 0) \ln E d E / \int_{0}^{\infty} f(E, 0) d E, \\
& \int_{0}^{\infty} f(E, 0) d E=1,
\end{aligned}
$$

Where $E$ is the energy transfer in a transition and $f(E, 0)$ the dipole oscillator strength DOS (Fano, 1963), wh1ch is related to the optical absorption coefficient (e.g. Barkyoumb and Smith, 1990). The Bloch parameter is defined by 
For the Thomas-Fermi atom, Bloch (1933) showed that $b$ is a constant.

For many gases, I-values have been determined with Eq. (3) (see, e.g., Zeiss et al., 1977; Jhanwar et al., 1983). The only metals for which I was calculated with Eq. (3) are Al (Shiles et al. 1980) and, partially, S1 (Bichsel, 1988). For heavy elements, insufficient information is available about $f(E, 0)$ to permit a determination of $I$.

For metals, the excitation function for the collective excitation of the valence electrons should be used in $\mathrm{Eq}$. ("plasmon excitations", e.g. Raether, 1980). Qualitatively, the influence of plasmons may be understood from the value of the most probable energy loss hf for valence electrons, given in Table VI; $h f_{V}$ was derived from electron energy-loss spectra given by Ahn et al. (1983). hf depends on the structure of the metal and the number of valence electrons and thus will not relate simply to $Z$.

A quantity related to $I$ is the plasma energy hi (Fano, 1963), defined by $(h f)^{2}=830.4 \rho \mathrm{Z} / \mathrm{A}$ (hf in $\mathrm{eV}, \rho$ the density of the metal in $\mathrm{g} / \mathrm{cm}^{3}$ ), shown in Table I. This quantity replaces the I-value in $S$ for very high particle energies. Clearly, hf depends strongly on the density, explaining the small values for $\mathrm{Pb}, \mathrm{Bl}$ and $\mathrm{Th}$. The small values of $\mathrm{hf}$, and hf for $\mathrm{Pb}$ compared to those for $\mathrm{Au}$ may explain in part why the experimental value of the Bloch parameter, $\mathrm{b}_{e}$ for $\mathrm{Pb}$ is smaller than that for Au.

Another approach to getting information about stopping power, I-values and shell corrections is to use the statistical atomic model (Bonderup, 1967). Values of I for atoms were calculated by Bichsel and Laulainen (1971) with this model using the relativistic wavefunctions of liberman et al. (1965, 1971). The resulting Bloch parameters, $b_{L}$ based on $\gamma=1.347$, are given in Table $I$. Similar results were obtained by Chu and Powers (1972). Values for the solids would differ by several percent; for light elements there are large differences: for $A l, b($ atom) $=9.56 \mathrm{eV}$, Dehmer et al. $(1975) ; b(s 011 d)=12.77 \mathrm{ev}$, Shiles et al. (1980); for si, 
$b($ atom $)=9.39 \mathrm{eV}, b($ solld $)=12.43 \mathrm{eV}$, Blchsel (1988). It must also be clearly understood that the DOS used in this model differs strongly from actual optical data (Johnson and Inokut1, 1983).

It is tempting to try to derive I-values from the well known experimental ionlzation energies $J_{1}(e . g$. Bearden and Burr, 1967). I have used an expression given by Sternheimer et al. (1984) ((their Eq. (8)); it was derived for a different purpose) to calculate $I$ from $J_{1}$, the plasma frequency hf and with an estimate of DOS for photon energies above the lonization energies expressed by a factor $\tau$. Values $b_{s}$ calculated with a constant value $\tau=2$ are given in Table $I$. These results demonstrate that one should resist this particular temptation.

The experimental results for $b$ from the present study are given in Table $I$, and are discussed in section III $B$. Experlmental values used by Andersen and Zlegler (1977), Janni (1982) and ICRU (1984) are also given.

\section{Shell corrections $C(v, z)$.}

\section{General review.}

In the Bethe theory, shell corrections must be calculated on a shell-by-shell basis:

$C(v, z)=\sum_{\nu} C_{\nu}(v, z)=C_{K}(v, z)+C_{L}(v, z)+C_{M}(v, z)+\ldots$

Usually, the dependence on particle speed $v$ is expressed in terms of the variable $\eta$ :

$\eta_{\nu}=\left(m v^{2} / 2\right) /\left(m v_{0}^{2} \cdot z_{\nu}^{2} / 2\right)=\left(m v^{2} / 2\right) / \epsilon \nu$

with $\epsilon_{\nu}=R Z_{\nu}^{2}, v_{0}$ the Bohr speed $\left(v_{0}=c / 137\right), R=m v_{0}^{2} / 2=13.6 \mathrm{eV}$ the Rydberg energy of the hydrogen atom, and $z_{\nu}$ the effective charge of the absorber atoms for electrons in shell $\nu$. The dependence of $C_{\nu}$ on the atomic number $\mathrm{Z}$ also enters via the ionization energy $J_{\nu}$, expressed in terms of: 
In principle (Janni, 1982), these functions should be calculated for each subshell in the atom (Bearden and Burr, 1967). Here, a somewhat simpler approach was used, as outlined below.

Shell corrections for $K$ - and L-shells were derived by walske (1952, 1956) with the nonrelativistic hydrogenic approximation. Recently, the corrections for the M-shells (B1chsel, 1983) and the L-subshells have been calculated (Bichsel, 1987), also with the hydrogenic approximation.

For the outer shells no calculations have been made, and a scaling procedure was used in which it was assumed that the shell-corrections for outer shells have the same shape as those for the inner shells (Hirschfelder and Magee, 1948; Blchsel, 1961; Janni, 1982). Vertical, $v_{\nu}$, and horizontal, $\mathrm{H}_{\nu}$, scaling factors were introduced:

$C_{\nu}=v_{\nu} C_{\mu}\left(\mathrm{w}_{\mu}, \mathrm{H}_{\nu} \cdot \eta_{\mu}\right)$

where. $\nu$ stands for any one of the outer shells and $\mu$ stands for the inner shell. Presumably, $\mathrm{H}_{\nu}$ would be proportional to the ratio of ionization energies, $J_{\mu} / J_{\nu}$, and $v_{\nu}$ related to the number of electrons in the shell. In order to assess the plausibility of this approach, it is instructive to compare the shapes of the known shell corrections. In Fig. 1, they are shown for $K, L$ and $M$ electrons in gold. The functions have been plotted in such a way as to coincide at the maximum value. Clearly, the functions are similar in shape, and the scaling procedure can be used with some justification, but the horizontal scaling factors $f_{\nu}$ given in the Fig. are only approximately proportional to the ionization energies $w_{\nu}$, and the vertical scaling factors $g_{\nu}$ are not well correlated with the number $n$ of electrons. At present it is not known how closely the hydrogenic calculations approximate the correct functions. Because empirical parameters $H$ and $V$ are used in Eq. (5), the degree of approximation cannot be assessed from experimental data for $S$. More accurate calculations are needed. 
Bonderup (1967) derived shell corrections from the stopping power of an electron gas (Lindhard and Winther, 1964) with electron density varying with distance from the nucleus ("local plasma model") and gave functions based on the LenzJensen model. Empirical functions for the shell corrections were given by Andersen and zlegler (1977) and by Janni (1982). Shell corrections for Au from these sources are shown in Fig. 2 .

2. Present approximation.

(a). Inner shelis (K, $L, M)$

The functions given by Walske (1952), Khandelwal (1968), and Bichsel $(1983,1987)$ were used. The effective charge, $Z_{\nu}$ in Eq. (4a), was assumed to be $n s$, where $n$ is the principal quantum number and $S$ the orbital exponent given by Clement 1 et al. (1967). For the $K$-shell, $z_{K}=Z-0.3$ was used. The quantities $\epsilon{ }_{\nu}$ and $W_{\nu}$ for some elements are given in Table II. From the variations in $w_{\nu}$ for the subshells and from the differences in shape seen in Fig. 1 it is evidently advisable to calculate $C_{\nu}$ for each inner subshell separately.

(b). Outer shells.

From the values of the scaling factors $g_{\nu}$ and $f_{\nu}$ in Fig. 1 we must conclude that for the outer shells there are no compeling choices for the scaling factors $\mathrm{H}_{\nu}$ and $V_{\nu}$ in Eq. (5). They must be chosen such as to give good agreement with experimental data.

The ionization energies for the outer shells of some of the heavy elements are given in Table III. In order to reduce the number of free parameters, and in view of the uncertainty of the choice of $\mathrm{H}_{\nu}$, it is reasonable to consider shell correction functions for groups of subshells for which the ionization energies are similar: $N_{I}$ to $N_{I I I} N_{I V}$ and $N_{V^{\prime}}$ and all the other shells. I have used this approach and have named the functions $\mathrm{C}_{\mathrm{N}_{1}}, \mathrm{C}_{\mathrm{N} 2}$ and $\mathrm{C}_{\mathrm{N} 3}$, using six parameters $\mathrm{H}_{1}$, $\mathrm{V}_{1}, \mathrm{H}_{2}, \mathrm{~V}_{2}$ and $\mathrm{H}_{3}, \mathrm{~V}_{3}$. For the first and second group, the number of electrons in the shells $\mathrm{N}_{I}$ to $\mathrm{N}_{V}$ is constant (18), and we would assume that the factors $v_{1}$ and $v_{2}$ should change 
slowly with $Z$, at most. It appears plausible to use initial values of $\mathrm{H}_{\nu}$ given by

$\mathrm{H}_{\nu}=\mathrm{J}_{\mathrm{M}_{\mu}} \sum \frac{\mathrm{n}_{\nu}}{\mathrm{J}_{\mathrm{N}_{\nu}}} / \sum \mathrm{n}_{\nu}$

where $n_{\nu}$ is the number of electrons in subshell $\nu$ (Table III). I found that values $\mathrm{H}_{1}$ and $\mathrm{H}_{2}$ calculated with this Eq. gave better agreement with experimental data for Au than values different by $\pm 20 \%$, and no further searches were made with different $\mathrm{H}_{1}$ and $\mathrm{H}_{2}$. Thus there were now only the parameters $v_{1}$ and $v_{2}$ for which values were undetermined. It was expected though that $v_{1}$ and $v_{2}$ should be near 1 . A further option was the cholce of the inner shell $\mu$ from which the outer shell functions are scaled. I have found the best agreement with experiments by using the functions $C_{M I I I}$ for $\mathrm{C}_{\mathrm{N} 2}, \mathrm{C}_{\mathrm{MV}}$ for $\mathrm{C}_{\mathrm{N} 1}$ and $\mathrm{C}_{\mathrm{N} 3}$.

For all electrons outside of $N_{V}$ (in gold a total of 33 electrons, with ionization energies between 0 and $108 \mathrm{eV}$ ) a single function $C_{N 3}(v, z)$ was obtained by scaling $C_{M V}$ with $\mathrm{H}_{3}$ and $V_{3}$ as free parameters $\left(\mathrm{H}_{3}\right.$ might be $2 \mathrm{H}_{2}$ or greater, and $\mathrm{V}_{3}$ might be expected to depend on $\mathrm{Z}$ ).

The method of determining the parameters $v_{1}, v_{2}, v_{3}$ and $\mathrm{H}_{3}$ is described in section IIH. It will be seen that these four parameters are ample to provide calculated values of the stopping power agreeing well with experimental data.

By choosing the shell corrections to fit experimental data, they will also compensate for errors in $L_{1}, L_{2}$ and $z^{*}$.

\section{Barkas and Bloch corrections, $I_{1}$ and $I_{2}$.}

The need for $z^{3}$ and $z^{4}$ corrections in the theory was established experimentally by Andersen et al (1977). Basbas (1984) discussed the problem in a general context. Bichsel (1990) analysed experimental data and found that for Au only an empirical function for $L_{1}$ approximated experimental data (extending from 1 to $4 \mathrm{MeV}$ ) well: 
$I_{1}(\beta)=0.002833 \cdot \beta^{-1.2}$.

Here, this expression has been used for all proton energles, and for all $z \geq 57$. These extrapolations are dublous.

The term $\mathrm{L}_{2}$ is written in the form derived by Bloch (1933):

$L_{2}=\psi(1)-\operatorname{Re}[\psi(1+i y)]=-y^{2} \sum_{j=1}^{\infty} \frac{1}{j\left(j^{2}+y^{2}\right)}$

where $\psi$ is the logarithmic derivative of the $\Gamma$ function, and $y=z v_{0} / v=z \alpha / \beta \quad(\alpha=1 / 137.036$ is the fine structure constant). For $y^{2} \ll 1$, the sum is equal to $1.202 \ldots \mathrm{L}_{2}$ does not depend on $Z$, but does include terms of all even powers of z. Possible errors in $I_{1}$ and $I_{2}$ will be compensated by the choice of the shell correction parameters.

E. Charge state corrections and nuclear collisions.

Bichsel (1990) found that it was not necessary to use any charge state corrections for protons and $\alpha$ with $T / M \geq 0.5 \mathrm{MeV}$ (M is the number of nucleons in the ion). For Li-ions, a reduced charge $z^{*} \leq 3$ appears to be needed for $T / M<2 \mathrm{MeV}$, but no definite form of $z^{*}$ could be derived from the experiments. For lower energies and heavier ions, the need for charge state corrections will be seen in the Figs. and in Table VIII.

Nuclear collisions contribute less than $0.1 \%$ to the stopping power at the energies considered here, and thus are neglected.

F. Mott correction $G$ and density effect, $\delta$.

Ahlen $(1978,1980)$ gave a close-collision correction $G(z, \beta)$ due to the Mott cross section. For $p$ and $\alpha$, a rough approximation is $G \approx a_{1} 2 \beta / 137$, where $-10<a_{1}<2$ for $0.3<T / M<30$ Mev. Thus this term is less than 0.1 for $p$ and $\alpha$, but will be more important for heavy ions (e.g. about 2 for $3000 \mathrm{MeV}$ (a 1ons). 
The algorithm used here for the density effect has been given by Sternheimer et al. (1984). It must be noted that approximations were made which may introduce errors of the order of 0.3 into $S_{t}$ at $T>100 \mathrm{MeV}$ (see Figs. 6.2 to 6.4 in ICRU-37, 1984). The effect amounts to less than 0.048 for 20 $\mathrm{MeV}$ protons in gold, and thus is only important for some of the measurements at high energies and for the heavy lons.

\section{G. Ranges and multiple scattering.}

Ranges were calculated from stopping power $S$ with the csda (continuous-slowing-down) approximation:

$R(T)=R\left(T_{1}\right)+\int_{T_{1}}^{T} d T^{\prime} / S\left(T^{\prime}\right)$

For present purposes, for protons, $T_{1}=0.4 \mathrm{MeV}$, and $R\left(T_{q}\right)$ was taken as the total pathlength given by Jann1 (1982). For 10 $\mathrm{MeV}$ protons in Au, this contribution amounts to less than 9 o of the total range. Due to multiple scattering, experimental projected ranges are shorter than $R(T)$. Corrections for this effect were given by Bichsel and Uehling (1960), Bichsel (1960), Berger and Seltzer (1964), Bichsel (1972), Janni (1982), and by Bichsel and Hiraoka (1989).

\section{H. Method for parametex determination.}

The parameters to be determined are the I-value and the scaling factors $\mathrm{H}_{3}$ and $\mathrm{V}_{\nu}$ of Eq. (5) for the outer shell corrections. They were found from experimental data with a least-squares-deviation procedure.

In earlier studies (e.g. Porter and Bryan, 1984), the Ivalue was introduced explicitly as a free parameter in the data analysis. This can be avolded with the following approach. Customarily, the deviation $\delta(\beta)=L_{t}(\beta)-L_{x}(\beta)$ is calculated, and the sum $\Sigma \delta^{2}$ is considered as a function of the five parameters. A best fit is obtained if the sum is a minimum. A variation of the parameter I can be avoided if the equation for $\delta(\beta)$ is rearranged as follows: 


$$
\begin{aligned}
\delta(\beta)+\ln I \equiv Y(\beta) \equiv & f_{1}(\beta)-C_{1}(\beta)-c_{0}(\beta)+z L_{1}(\beta) \\
& +L_{2}(\beta)-L_{X}(\beta)
\end{aligned}
$$

where $f_{1}(\beta)=f(\beta)+(G(z, \beta)-\delta(\beta)) / 2$

$$
\begin{aligned}
& C_{1}(\beta)=\frac{C_{K}(\beta)+C_{L}(\beta)+C_{M}(\beta)}{2} \\
& C_{0}(\beta)=\frac{C_{N 1}(\beta)+C_{N 2}(\beta)+C_{N 3}(\beta)}{2} \text { and }
\end{aligned}
$$

the dependence on $\mathrm{z}$ is not indicated. This expression implicitly contains, in $C_{0}(\beta)$, the four free parameters $\mathrm{H}_{3}, \mathrm{~V}_{\nu}$ of Eq. (5). If there are no systemat1c errors in the theory, we expect that $Y(\beta)$ will be a constant (but subject to stochastic errors of the data), and $\exp (Y(\beta))=I_{X}(\beta)$ is an experimental I-value for each data point. We define $Y_{a}$ as the average of $\mathrm{p}$ experimental values of $\mathrm{Y}(\beta)$ :

$Y_{a}=\sum_{p} Y(\beta) / p$

and by assuming $Y_{a}=\ln I$, the average deviation $\sigma$ defined by

$\sigma^{2}=\sum\left(Y_{a}-Y(\beta)\right)^{2} /(p-1)$.

is the same as $\sum \delta^{2} /(p-1)$. With this approach, the parameter search is performed. for a space reduced by one dimension (1.e. a five parameter search is reduced to a four parameter search). $\sigma^{2}$ depends on the parameters $H_{3}, V_{\nu}$ and can be considered as a function of the four-dimensional space with coordinates $\mathrm{H}_{3}, \mathrm{~V}_{V}$. The smallest $\sigma^{2}$ define sets of parameters giving best fits to experimental data.

It was found that there were many local minima of $\sigma^{2}$, and therefore the method of steepest descent was not sultable for the parameter determination; a grid search was used instead. The parameters for small $\sigma^{2}$ were recorded, and the associated functions $Y(\beta)$ were plotted versus particle speed $\beta$ and examined for systematic deviations. If the deviations ( $Y_{a}-$ $Y(\beta))$ were randomly distributed, or if they deviated systematically by much less than the experimental error, satisfactory values of the four parameters and the corresponding I-value 


$$
I_{a}=\exp \left(Y_{a}\right)
$$

had been found. $I_{2}$ is subject to systematic errors of $S_{x}$.

\section{EXPERIMENTAL DATA.}

For most elements, only the experimental data for protons were used for the parameter determination. The data for $\alpha$ particles in Au were used 1mplicitly by the determination of the function $I_{1}$ for the Barkas effect (Blchsel, 1990). For measurements below $30 \mathrm{MeV}$, relative to $\mathrm{Al}$ or $\mathrm{Cu}$ (e.g. Burkig and Mackenzie, 1957), theoretical values from Blchsel (1972) were used to calculate $\mathrm{S}_{\mathrm{x}}$.

I have found that systematic differences occur between experimental data from different sources (see the Figs.) and that the uncertainties $\sigma_{e}$ assigned by the authors to their experimental data represent only a qualitative measure of $\sigma_{e}$. This means that a simultaneous $\chi^{2}$ analysis of several data sets is not practical. Therefore, best fit parameters were determined for each data set, and average values of the parameters were then used. For some data sets where stochastic errors were less than 1\% (e.g. Semrad, 1990: Oberlin et al., 1980, 1982; Matteson et al., 1978), a smooth function obtained from a three parameter fit $\left(\mathrm{H}_{3}, \mathrm{~V}_{3}\right.$ and I) has been used to represent the data in the Figs.

For gold, I designed an average experimental data set for proton energies above $0.3 \mathrm{MeV}$. Between 0.3 and $1.5 \mathrm{MeV}$, data by Luomajurv1 (1979), Semrad (1990), Andersen and Nielsen (1981) and Santry and Werner (1981) were used and given about equal welght. Between 1.5 and $3 \mathrm{MeV}$, the data by Andersen and Nielsen (1981) were reduced by $0.8 \%$. Above $3 \mathrm{MeV}$, the data by the Nara group (Ishiwar1 et al., 1984; Shiom1 et al., 1986) and those by Shrensen and Andersen (1973) were welghted inversely with their quoted errors. Other data were not used.

For each experimental, $S_{X}(T)$, and theoretical, $S_{t}(T)$, value, the relative difference $x(T)$ was determined:

$r(T)=\left(S_{t}(T)-S_{x}(T)\right) / S_{x}(T)$ 
Values of $r(T)$, in percent, are plotted in the Figs. The average standard deviation $\sigma_{\mathrm{x}}$ for an experimental data set with $\mathrm{p}$ values was defined by

$\sigma_{x}^{2}=\sum r(T)^{2} /(p-1)$.

$r(T)$ and $\sigma_{x}$ should be compared with the errors $\sigma$ of $S_{x}$ given by the authors, shown in Tables VI, VIII, and in the Figures. If, in general, $|r(T)|$ is less than $\left|\sigma_{e}\right|$, I consider the theory to be adequate. If $|r(T)|$ exceeds $\left|\sigma_{e}\right|$, there may be systematic errors of the theory or the experiments, and the reader is invited to choose which to believe. Symbols used in plotting the data are given in Table $V$.

\section{RESULTS OF PARAMETER SEARCHES.}

\section{A. Shell correction parameters and I-values.}

In principle, the parameters could be different for each element. After a preliminary four parameter search for several elements, I found that $V_{1}$ and $V_{2}$ could be assumed to be constant for all $\mathrm{Z}$. This assumption may have to be changed as more accurate data become avallable. From an examination of the experimental data I concluded that only for gold there were enough data to permit a meaningful four parameter search. For other elements, a two parameter search for $\mathrm{H}_{3}$ and $V_{3}$ was made, and $1 t$ was possible to find flxed values of $\mathrm{H}_{3}$ which were valid for groups of elements. Only for $v_{3}$ was it necessary to assume a dependence on Z. Eventually, the I-value resulting from Eq. (10b) was the only truly free parameter.

With the search program based on the use of Eq. (9), uncertainties cannot readily be stated for the parameters (or the stopping power function $s_{t}$ ). It will be seen from Figs. 6-13 that this is not a major problem.

The four parameters $\mathrm{V}_{1}, \mathrm{~V}_{2}, \mathrm{H}_{3}$ and $\mathrm{V}_{3}$ for the outer shell corrections, Eq. (5), were determined for the average data set for gold with the search procedure outlined in section II H. The grid search for local minima of $\sigma^{2}$, Eq. (10a), was performed with 20 to 30 values of each of the four parameters, with the initial value of $\mathrm{H}_{3}$ about $1.5 \cdot \mathrm{H}_{2}$, the final value 
about $3 \cdot \mathrm{H}_{2}$; the initial $\mathrm{V}_{\nu}$ equal to 0.5 and the final values up to 3. In each search, up to 500,000.p values of $s_{t}$ were calculated. Results of the search with $\mathrm{H}_{1}$ and $\mathrm{H}_{2}$ from Table III are given in Table IV. The 4 parameters $\mathrm{V}_{1}, \mathrm{~V}_{2}, \mathrm{~V}_{3}$ and $\mathrm{H}_{3}$ giving a local minimum of $\sigma^{2}$ are listed, together with $\sigma^{2}$, the $I-v a l u e$ and $\sigma_{x}$ (Eq. (12)). Since for all these parameter sets the average standard deviation $\sigma_{x}$ between experimental and calculated values is less than even the smallest quoted experimental error $\sigma_{e}( \pm 0.3 \%)$, they all could be used to approximate the average data set well. Evidently, this data set is insufficient to determine the parameters uniquely (this of course is also true for the individual sets). Because the number of electrons associated with $v_{2}$ is larger than that for $v_{1}$, a value $v_{2}$ larger than $v_{1}$ is desirable. Thus, the parameters $V_{1}=1.25, V_{2}=1.4$ are henceforth used for all elements, and the value $\mathrm{H}_{3}=13$ should be valid for elements neighbouring gold in the periodic table.

It $1 \mathrm{~s}$ expected that the parameters $\mathrm{H}_{3}$ and $\mathrm{V}_{3}$ associated with electrons in the outermost shelis ( $N_{V I}$ to $\left.Q\right)^{3}$ will depend on the atomic number $Z$. Therefore $I$ made a two parameter search for $\mathrm{H}_{3}$ and $\mathrm{V}_{3}$ for best fits for all elements. I found that for $\mathrm{Z} \geq 73$ a value $\mathrm{H}_{3}=13$ gave satisfactory fits; of course, the values $V_{3}$ and $I$ varied for each experimental data set. Values of $V_{3}$ are plotted in Fig. $3:$ a tendency toward an increase of $\mathrm{V}_{3}$ with $\mathrm{Z}$ can be discerned, especially for the data from Denmark and Nara. Since $v_{3}$ should be related to the number of outermost electrons, $n_{0}=Z-46$, the function

$$
v_{3}=(Z-46) / 25
$$

was chosen to represent this parameter. The value of $V_{3}$ is quite sensitive to experimental uncertainties because $C_{\mathrm{N} 3}$ at 1 $\mathrm{MeV}$ contributes only about 10 \% to the stopping number $\mathrm{L}$, Eq. (2), and only 1 s at $6 \mathrm{MeV}$.

For the elements with $57 \leq \mathrm{z} \leq 73$, the results of a two parameter search for $\mathrm{H}_{3}$ and $\mathrm{V}_{3}$ are shown in Table VI. Note that $\sigma_{x}$ for some data exceeds $\sigma_{e}$ slightly. This may mean that the authors underestimate $\sigma_{e}$ (see the Figs.). No definite trend of $\mathrm{H}_{3}$ with $\mathrm{Z}$ can be seen, but it appears that a larger value $\mathrm{H}_{3}$ is appropriate for $\mathrm{Z}<60$ than for $\mathrm{Z}>60$, thus $\mathrm{H}_{3}=50$ and 
$\mathrm{H}_{3}=25$ were chosen respectively. For $\mathrm{Z}=73$, a smaller value is indicated, and the value for $\mathrm{Au}\left(\mathrm{H}_{3}=13\right)$ was used. Then, a one parameter search was made for $V_{3}$. Values giving best fits are shown in Fig. 4 and in Table VIa, together with $I_{a}$ and $\sigma_{x^{\circ}}$ Note that $\sigma_{x}$ may change little while I may change much. This means that the change in $\mathrm{H}_{3}$ and $\mathrm{V}_{3}$ is compensated partly by the change in $I_{a^{\circ}}$ In Fig. 4 , no systematic trend of $V_{3}$ with $Z$ can be seen below or above $Z=60$, therefore $I$ chose constant values, approximately equal to the average for all data, viz. $v_{3}=3.85$ for $z<60, v_{3}=2.3$ for $z>60$.

Finally, the average value $I$ for each data set was determined with the parameters defined above and the values $b_{a}=I_{a} / Z$ are shown in Fig. 5. Again the $\sigma x$ are less than $\sigma_{0}$ with these I for most data sets (Table VIa), and in general they are only silghtly larger than $\sigma_{x}$ for the one and two parameter fits. The fluctuations in $I_{a}$ for each $z$ evidently are in part an expression of the systematic differences between experimental data, but because the values were obtained from data at different enexgy ranges, they may also indicate possible problems in the assumptions about the theory.

\section{B. Average I-values for the elements.}

For the elements with a single data set (Sm, U), the analysis is finished: the experimental value of I for the element is $I_{e}=I_{a}$. For elements with several sets of experimental data, we must select a value $I_{e}$ a weighted average of I ( I by the definition of Eq. (2a) is a property of the material). Greater weight was assigned to values from higher energies. The values selected are shown in Table I. They are only valid in the context of the other parameters selected here, and of the experimental data used in the analysis. An uncertainty of $I_{e}$ of $\pm 1.5 \%$ to $\pm 5 \%$ should be assumed. A comparison with other experimental values of $I$ is only meaningful to show trends with $Z$.

It is notable that (except for $W, B i$ and $T h$ ) $b$ and the value $b_{L}$ calculated with the local density model differ by less than $\pm 5 \%$ (the average deviation is $(0.6 \pm 3.3) \%$ ), even though $b_{I}$ was calculated for single atoms, while $b_{e}$ was 
measured for the metal. Some of the variation in $b_{e}$ must be related to the variation in hf and in the plasmon energy hf $v$ of the valence electrons. In particular, this may explain the difference in $b_{e}$ between $A u, P b$ and $B 1$. It appears advisable to be suspicious of the values of $b_{e}$ for $W, B i$ and $T h$. Fluctuations in $b_{e}$ for neighbouring $z$ may be indicative of systematic errors in the measurements.

The differences between $b_{e}$ and $b_{J}$ and $b_{A}$ are explained in part by the fact that a larger set of data was used here. It must be understood clearly that values $b_{e}$ will change as further experimental data become avaliable.

The I-values for $\mathrm{Pb}$ and $U$ for the proton energies below $30 \mathrm{MeV}$ are less than those indicated from the higher energies. Further studies appear to be needed.

A determination of I-values with an uncertainty of less than 2 from other methods (e.g. Shiles et al., 1980) is highly desirable.

$v$. Comparison of theory and experiment.

A. Protons.

The comparison between experimental data $S_{x}$ and theoretical functions $S_{t}$ for $T \leq 30 \mathrm{MeV}$ is made in Figs. ${ }^{6} 6-13$. The relative difference $r(T), E q . \quad(11)$, is shown as a function of kinetic energy $T / M$ of the protons. The authors' experimental uncertainties are shown at only a few energies. There is no evidence to invalidate the theory. It is somewhat surprising that the theory agrees with experiments at energies $T$ well below $1 \mathrm{MeV}$. There are no general trends for $r(\mathrm{~T})$ to be definitely larger than 0 , thus no need for a reduced effective charge ${ }^{\star}$ is evident. For Ta, Fig. 7 , the agreement between theory and experiments as well as between different experiments is poor. While the data by Luomajurvi (1979) for $\mathrm{p}$ in $\mathrm{Ta}$ differ considerably from theory, they agree quite well for $W$ and Au.

Some experimental data not included in the Figs. are considered next. For Th, data by Teasdale (1949), Sonett and Mackenzie (1955) and Burkig and Mackenzie (1957), with $\mathrm{H}_{3}=13$, 
$V_{3}=1.76$ result in $I_{2}=766 \mathrm{eV}, \sigma_{\mathrm{x}}= \pm 0.7 \%$. Energy loss measurements for protons with initial energies $T_{1}$ between 14 and $25 \mathrm{MeV}$ in thick absorbers were made by Bichsel and Tschalar in 1966 with the method described by Tschaldy (1967) and Tschalur and Bichsel (1968). The residual energies $T_{f}$ were measured with silicon detectors and corrected for multiple scattering. A theoretical thickness $t_{t}=R\left(T_{f}\right)-R\left(T_{f}\right)$ was obtained from range energy tables calculated with Eq. (8). The uncertainty of the energy-measurements (less than $\pm 0.1 \%$ for $T_{1}$ ' about $\pm 24 \mathrm{keV}$ for $T_{f}$ ) corresponds to an uncertainty of no more than $0.5 \%$ in calculated thicknesses $t_{t}$. The results have not been published so far because the theory used in 1967 was inadequate. Experiment and present theory are compared in Table VII. For both metals, a systematic trend with energy is seen. Larger I-values would provide somewhat better agreement.

Sakamoto et al. (1989) measured the stopping power for $73 \mathrm{MeV}$ protons in ten elements with an uncertainty of $\pm 0.7 \%$. Data are shown in Table VIII. OnIy the value for $\mathrm{Pb}$ exceeds $\sigma_{e}$ significantiy. A value $I=855 \mathrm{eV}$ would be needed to achieve $r=0$ for $\mathrm{Pb}$. For $\mathrm{Al}, r=0.3 \%$ and for $\mathrm{Cu}, r=0.8 \%$ from the tables described below.

Several measurements with high energy protons have been reported. They are listed in Table IX. Usually the range of particles with a fixed energy was measured in $A l$ or $C u$. Then a given layer in the principal absorber was replaced by another material, and the range measurement was repeated. The ratio of thicknesses of materials causing the same energy loss was thus determined. In order to obtain the stopping power for the second absorber, that of the first absorber must be known. Therefore, stopping power tables for $A l$ and $C u$ were calculated with the shell corrections given in ICRU-37 (1984), with $I(A I)=166 \mathrm{eV}, I(C U)=322 \mathrm{eV}$ and the density effect of Section II $E$. No corrections for straggling, multiple and nuclear scattering and nuclear reactions were made beyond those made by the authors. It must be noted that the change in the multiple scattering and the straggling in the second absorber will lead to changes in the total range (of the order of $0.5 \%$ ) which have not been considered so far (Bichsel and Hiraoka, 1989). 
It was found that the rat1o of absorber thicknesses even for falrly large energy losses (e.g. $T_{1}=340$ to $T_{f}=270 \mathrm{MeV}$ ) differs by no more than $0.1 \%$ from the ratio of stopping powers at the mean energy (1.e. $300 \mathrm{MeV}$ ). This can readily be confirmed from existing range tables (Bichsel, 1972). Therefore, $S_{x}$ was calculated from the ratio of thicknesses ("mass stopping power") given by the authors and the theoretical stopping power of the reference material (Al or $\mathrm{Cu})$ at the mean energy $\mathrm{T}$ given by the authors.

For Bakker and Segré (1951), $T_{1}=340 \mathrm{MeV}, T_{f} \approx 270 \mathrm{MeV}$, $\sigma_{e}= \pm 1 \%, S_{x}$ was calculated with $S_{t}$ of both $A I$ and $C u$, and the average is given in the table. For $U$, $\sigma$ exceeds $\sigma$ slightly. For the ratio $S_{x}(A I) / S_{x}(C u)$, the difference of $1 \frac{8}{8}$ may be indicative of systematic errors in theory or measurement.

Barkas and von Friesen (1961) with $750 \mathrm{MeV}$ protons measured thicknesses of several materials relative to the equivalent thicknesses of $\mathrm{Cu}$ at several depths in a copper absorber. Theoretical values of the stopping power of $\mathrm{Cu}$ were used to obtain $S_{x}$ for $P b, U$ and $A I$. Since the estimated experimental exror is considerably less than $1 \%$, the relative differences $r$ between theory and experiment are disturbingly large. Larger I-values would be needed to get $r=0$. If the measurements had been made relative to Al, the average $r$ for $\mathrm{Pb}$ would be $0.5 \%$, for $U, 0.3 \%$.

Vasilevskil and Prokoshkin (1967) measured stopping power of $\mathrm{Pb}$ relative to $\mathrm{Cu}$ for $\mathrm{p}, \mathrm{d}$ and $\alpha$. The data are listed in Table IX at the equivalent proton energy. The absolute values of $S_{x}$ given for $C u$ by these authors (shown in Table IX) were used to calculate $\mathrm{S}_{\mathrm{x}}$ for $\mathrm{Pb}$. For $\mathrm{Pb}$, the agreement between theory and experiment is good, but the experimental values for $\mathrm{Cu}$ exceed the theoretical values by $0.8 \%$ on the average.

Vasilevsk11 et al. (1969) measured the stopping power of $\mathrm{Pb}$ relative to that of $\mathrm{Al}$ with the method used by Barkas and von Friesen (1961) with an initial beam energy of $660 \mathrm{MeV}$. The theoretical stopping power function for Al was used to calculate $S_{x}$ for $\mathrm{Pb}$. Here, on the average, $S_{t}$ for $\mathrm{Pb}$ exceeds $\mathrm{S}_{\mathrm{x}}$ by $1.3 \%^{\mathrm{x}}$. It is interesting to include the experimental 
data for $\mathrm{Cu}$ : in contrast to the data by Barkas and von Friesen, there is essentially no difference between theory and experiment.

From the data at energies above $20 \mathrm{MeV}$, a higher I-value (which would reduce $S_{t}$ ) is indicated for $\mathrm{Pb}$ and $\mathrm{U}$. The need for further correction terms in the theory must also be considered.

\section{B. Helium and heavier lons.}

Selected data for $\alpha$ are shown in the Figs. and in Table VIII. The values of $r$ generally increase with decreasing $T / M<0.5 \mathrm{MeV}$, indicating the need for a charge state correction.

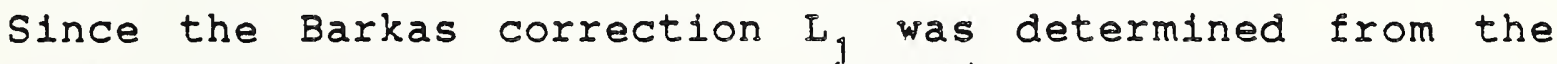
data for Au by Andersen et al. (1977), we can expect the agreement between $S_{x}$ and $S_{t}$ for $\alpha$ to be good. This is indeed the case. Agreement within experimental errors was also found for L1-ions (Bichsel, 1990).

For Au, only the data by Fontell and Luomajurvi (1979) (dashed-dotted line) and by Matteson et al. (1978) (solid line near $T / M=0.5 \mathrm{MeV}$ ) are shown 1n $\mathrm{Fig}$. $6 \mathrm{a}$. Other data are shown in Table VIII.

For the experimental values by Anthony and Lanford (1982) for C-ions in gold, a charge state correction is needed if it is assumed that $I_{1}$ is correct for $z>3$.

The experimental data by Datz et al. (1977) appear to have large systematic errors. The need for a charge state correction or for changes in $I_{1}, L_{2}$ etc. appears for $z>4$.

Experimental data by Ishiwarl et al. (1971, 1977, 1978) and data by Takahashi et al. (1983) generally agree with theory. For the C-ions, $I_{1}$ and $I_{2}$ amount to 8 and $5 \%$ of $I_{\text {, }}$ respectively. The expression given by Eq. (6) seems to be valid for $z=6$ at this energy. The Mott term amounts to less than $0.2 \%$. For $\mathrm{Pb}$, an I-value of $747 \mathrm{eV}$ would give better agreement with experiments. 
The data for ${ }^{16} \mathrm{O},{ }^{36} \mathrm{Ar},{ }^{40} \mathrm{Ar}$ and ${ }^{40} \mathrm{Ca}$ ions traversing $\mathrm{Ta}$ and Au agree well with calculated values, except for 0-ions with $\mathrm{T}<100 \mathrm{MeV}$ in $\mathrm{Au}$, where a charge state correction appears to be necessary. The data at $75 \mathrm{MeV}$ seem to be wrong.

A function correcting for charge state 2 * 1 s needed for $T / M<(z-1.5) \mathrm{MeV}$. The data presented here are not sufficient to arrive at a quantitative description of $z^{*}(\beta)$.

\section{Range measurements.}

Range data were not suitable for the determination of the shell correction parameters. In principle, I-values could be obtained from them. In Table $x$, experimental ranges, $R_{X^{\prime}}$ are compared with calculated ranges $R_{t}, E q . ~(8)$.

The ranges of protons in Au measured by Bichsel et al. (1957), were corrected by the multiple scattering corrections given by Blchsel and Uehling (1960). They are in good agreement with the theory. Asymmetrles in the rangestraggling function (Lewis, 1952; Tschaldy, 1968; Bichsel and Hiraoka, 1989) have not been taken into account yet.

The ranges for protons in lead measured by Bloembergen and van Heerden (1951) $\left(\sigma_{\mathrm{e}} \approx \pm 0.5 \%\right.$ to $\left.\pm 1 \%\right)$ are given uncorrected for multiple scattering. They exceed the calculated values on the average by $(0.2 \pm 0.3) \%$. Since the multiple scattering correction amounts to $\approx 1.78$ (Bichsel, 1972), the calculated values are too small by this amount. An I-value of $860 \mathrm{eV}$ would be needed to give calculated ranges agreeing with measured values, corrected for multiple scattering. It must be noted that the multiple scattering corrections given by Janni (1982) are about 50 larger.

The ranges of protons in lead, measured by Mather and Segre (1951), corrected for multiple scattering (Bichsel, 1960; Berger and Seltzer, 1964) agree well with calculated values. The ranges measured in $\mathrm{Al}$ and $\mathrm{Cu}$, though, are 1 to and 1.58 less than the theoretical ones.

A range measurement by Vasilevskil and Prokoshkin (1967) for $620 \mathrm{MeV}$ protons in $\mathrm{Pb}$ relative to the range in $\mathrm{Al}$ exceeds 
the calculated range by $1.5 \%$.

The corrected ranges $R_{x}$ for $750 \mathrm{MeV}$ protons in $\mathrm{Pb}$ and $U$ measured relative to the range in $\mathrm{Cu}$ by Barkas and von Friesen (1961) exceed the calculated ranges $R_{t}$ by $1.2 \%$. The range for Al is also given. It agrees well with $R_{t^{\prime}}$ in contrast to the data for the stopping powers in Table IX.

We see that for three out of four sets of range measurements for $\mathrm{Pb}$ a larger I-value is indicated than from the stopping power data.

\section{OSE OF THE THEORY FOR LOW ENERGIES.}

The expression for the stopping number I of Eq. (2) contains several terms which change quite rapidly with particle energy at small speeds. This can be seen in Table XI, where the terms of Eqs. (2) and (2a) are shown for protons in gold. The shell corrections are combined into "inner shells", $C_{i}$ and "outer shells" $C_{0}$ (Eq. (9)). The high speed approximation is defined by $L_{B}=f(\beta)$ - ln I, usually called the "Bethe approximation". For E>l MeV, $I_{B}$ differs by no more than $10 \%$ from $I$, but the sum of the corrections still amounts to $1.5 \%$ at $100 \mathrm{MeV}$ (the Mott term G and the density correction $\delta$ amount to less than $0.1 \%$ and are included in $f(\beta))$.

With decreasing energy, the various correction terms begin to contribute increasing amounts to $\mathrm{L}$. Around $1 \mathrm{MeV}$, the net contribution from the shell corrections, $c_{1}+c_{0}$ is almost zero. Below about $0.5 \mathrm{MeV}$, the major contribution to $I$ is from $C_{1}$ ! Clearly, the values for $\mathrm{I}$ below about $3 \mathrm{MeV}$ depend strongly on the values of the parameters used, and it is quite remarkable that most experimental data agree well with theoretical values at small energies for protons as well as for $\alpha$.

All the terms in Eqs. (2) and (2a) have a well defined physical meaning even at the smallest energies listed here, and therefore, no definite energy can be given at which the theory is invalid. On the other hand, the magnitude of each of the terms is not well determined theoretically. If for 
example different functions were used for $L_{1}$ and $L_{2}$, changes in $\mathrm{H}_{\nu}$ and $\mathrm{V}_{\nu}$ could compensate for most changes. For heavier lons, deviations between theory and experiment would be accommodated by a charge state correction which would require further free parameters.

\section{TABLES OF STOPPING POWER.}

Values of stopping power for $p$ and $\alpha$ calculated with the present theory are given in Tables XII and XIII. They are compared with other tabulations in Fig. 14. Andersen and ziegler (1977) published an evaluation of experimental stopping power data for protons. For energies greater than 1 $\mathrm{MeV}$, they used $5 i x$ free parameters to calculate the stopping power (see their Table 1, p.16: the parameter $A_{6}=5.099 \cdot 10^{-4} \mathrm{Z}$ is not a free parameter; $A_{7}=2 \mathrm{mc}^{2} /$ I is a free parameter and corresponds to $I_{e}$ in the present paper; the other five parameters, $A_{8}$ to $A_{12}$, show a systemat1c dependence on $Z$, but are not related to the parameters $\mathrm{H}_{\nu}$ and $V_{\nu}$ used here). For E<1 Mev, four parameters were used.

Jannt (1982) gave stopping powers for protons. He used the scaling procedure of Eq. (5) to obtain shell corrections for each subshell from Walske's (1956) L-shell corrections. Data from the tables by williamson et al. (1966) are also shown in Fig. 14. Data for $\mathrm{p}$ in $\mathrm{Pb}$ above $1 \mathrm{MeV}$ in Bichsel (1972) differ by less than 18 from present values. A major reason for the relatively large differences below $2 \mathrm{MeV}$ is the inclusion in the present study of the data by knudsen et al. (1980), Sirotinin et al. (1984) and Luomajarvi (1979) (see Table VI) which were not avaliable for the eariler evaluations.

For all the tables, the differences seen in Fig. 14 are in part due to differences in the choice of the I-values (see Tables $I$ and $X$ ), but there are also considerable differences in the shell corrections (see Fig. 2).

A comparison of the proton stopping power tables of Andersen and ziegler (1977) and the tables for $\alpha$ particles by Zlegler (1977) was made by Blchsel (1990). 


\section{CONCIUSIONS.}

Initially, the theory presented here contained seven free parameters: $H_{\nu}$ and $V_{\nu^{\prime}} \nu=1,2,3$ and $I_{a^{\prime}}$ in addition to the cholce of $Z_{\nu}$ for the $L$ - and M-shells (see Table II). After preliminary searches, $\mathrm{H}_{1}$ and $\mathrm{H}_{2}$ were chosen according to Table III, while $V_{1}$ and $V_{2}$ were determined in parameter searches from the averaged data for protons traversing gold, and were assumed to be constant for the other elements. Finally it was found that constant values of $\mathrm{H}_{3}$, for groups of elements, with $V_{3}$ given as a function of $Z$, and $I_{2}$ as the only free parameter gave good agreement with experiments for protons, $\alpha$-particles (Figs. 9-13) and some heavier lons (Table VIII) for all elements with $\mathrm{z} \geq 57$. For gold, I estimate the uncertainty of the theory to be $\pm 1 \%$ below $3 \mathrm{MeV}, \pm 0.5 \%$ between 3 and $20 \mathrm{MeV}$, 1 above $20 \mathrm{MeV}$. For other elements, it may be \pm 2 to 3 below $3 \mathrm{MeV}, \pm 1 \%$ above. The influence of the uncertainty of the Ivalue must be added. For $\mathrm{T}>30 \mathrm{MeV}$, further correction terms may be needed.

The present approach is plausible insofar as it includes all of the elements of current thoughts about Bethe-Bloch theory. It relies heavily on the experimental data for the determination of the parameters though. In examining the data for individual experiments for various $Z$ in Tables VI and VIA it is seen that a single experimental data set cannot be expected to provide the parameters $\mathrm{H}_{3}, \mathrm{~V}_{3}$ and $\mathrm{I}_{2}$ suitable for other data. Thus it appears inadvisable to determine parameters on the basis of data for a single data set, especially if they extend over a restricted energy range; and earlier studies (e.g. Bichsel, 1967; Porter and Bryan, 1980) are only applicable for the particular sets of experimental data used in their analysis.

If the theory is to be used for elements not listed in Table I, an I-value must be chosen. This could be done, e.g., by using $b_{e}$ from a neighbouring element or a calculated value of $b_{L}$.

Many systematic errors of unknown magnitude are associated with the theoretical functions used here. Examples are: 
1. use of nonrelativistic hydrogenic wave-functions (Append1x),

2. use of scaling procedure for the calculation of the shell corrections,

3. extrapolation of empirical $I_{1}$ to lower energies and different $\mathrm{Z}$,

4. Influence of the approximations used by Bloch in his derivation of $\mathrm{L}_{2}$,

5. neglect of higher terms in the Born approximation,

6. approximations used for the Mott term and the density effect,

7. neglect of charge exchange effects (e.g. Arnau et al., 1990).

In addition, systematic errors of the experimental data cannot necessarily be discerned. An example is the modification of the Andersen et al. (1977) data for Au by Andersen and Nielsen (1981). Therefore the results for $I_{P}$ based on a single set of data (1.e. $\mathrm{Ce}, \mathrm{Pr}, \mathrm{Sm}$, Ho, $\mathrm{Th}, \mathrm{U}$ ) must be considered to be tentative. Furthermore, the results for $\mathrm{Ta}$ (FIg. 7) do not inspire much trust in the experiments or the theory. Only the results for $\mathrm{Au}$ and maybe $\mathrm{Pb}$ can be considered more than tentative. I would be surprised though if new measurements would show the need for changes in the basic parameters of Tables II and III, and in $V_{1}$ and $V_{2}$. Measurements for proton energies between 0.5 and $6 \mathrm{MeV}$ for several elements with an uncertainty of no more than $0.3 \%$ would demonstrate the $\mathrm{Z}$-dependence of $\mathrm{H}_{3}$ and $\mathrm{V}_{3}$ more clearly. similar measurements would be required to establish values of $\mathrm{H}_{3}, \mathrm{~V}_{3}$ and $\mathrm{I}$ for compounds.

Further developments of the theory appear to be tedious and may not be worthwhile unless further measurements show a need for them. A better approximation for $L_{1}$ could be determined by measurements at $0.5 \leq \mathrm{T} / \mathrm{M} \leq 2 \mathrm{MeV}$ at least for protons and $\alpha$-particles with an error of less than $0.3 \%$.

The independent determination of I-values from Eq. with an uncertainty of less than $\pm 2 \%$ is desirable (1t would help e.g. with the problems with the data for $\mathrm{Ta}$ ). Accurate $x$-ray absorption measurements and electron energy-loss data similar to those by Ahn et al. (1983) would be needed for 
this purpose. Such I-values would also help in establishing the errors of the scaling factors $\mathrm{H}_{\nu}$ and $\mathrm{V}_{\nu}$ - or they might demolish the present approach.

While approximations better than the nonrelativistic hydrogenic calculations for $K$ - and $L$-shell excitations have been made for collision cross sections (reviewed e.g. by Cohen and Harrigan, 1985), these calculations st1ll differ by large amounts from experimental data at low particle speeds. It is thus an open question whether corresponding calculations for the shell corrections would be helpful.

It should be explored whether the differences between theory and experiments for stopping powers and ranges at energies above $30 \mathrm{MeV}$ indicate the need for further correction terms in the theory.

\section{ACKNOWLEDGMENTS .}

I am grateful to be able to use the computer facilities of the Nuclear Physics Laboratory at the university of washington; and for the support by the Greenwalt family. 
APPENDIX: REIATIVISTIC EFFECTS IN ABSORBER ATOM.

Leung (1989) described a correction to the Bethe theory which he obtained from considering relativistic effects for the atomic electrons. For $A u$, he estimated an increase of $S$ of about 2 due to this effect. The change was related to relativistic corrections to the Bethe sum rule described by Rustgi et al. (1988). The introduction of this correction term into the present analysis [with the expression given in Leung's Eqs. $(13)$ and (14)] changes the coefficients $H$ and $V$ for outer shell electrons, and decreases the I-values. For an average data set for $\mathrm{Pb}$, consisting of the data by Ishiwari et al. (1984) and Sorensen and Andersen (1973), the following three parameter best fit was obtained: $H_{3}=12, V_{3}=2$ and $I=720$ $\mathrm{eV}$, with $\sigma_{\mathrm{x}}= \pm 0.08 \%$. The fit is as good as that shown in Fig. 7. If these parameter values are used for all the high energy data for $\mathrm{Pb}$, the average value of $r$ is $(0.2 \pm 0.9) \%$, compared to $(1.4 \pm 0.9) \%$ for the standard parameters. Thus the Leung correction to the stopping power function brings the theory into closer agreement with experiment at the higher energies, and it appears desirable to explore this effect in more accurate studies. Also, more accurate measurements at both low and high energles would be useful to assess the accuracy of this correction. 


\section{References}

Ahlen, S. P., 1978, Phys. Rev. A 17, 1236

Ahlen, S. P., 1980, Rev. Mod. Phys. 52, 121

Ahn, C. C.,O. I. Krivanek, R. P. Burgner, M. M. Disko and P. R. Swann, 1983, "EELS Atlas", HREM Facility, Arizona State Univ., Tempe, AZ 85287 .

Andersen, H. H., C. C. Hanke, H. Sфrensen and P. Vajda, 1967, Phys. Rev. 153, 338. The gold data were repeated exactly in the next ref.

Andersen, H. H., H. Simonsen, H. Sфrensen and P. Vajda, 1969, Phys. Rev. 186,372

Andersen, H. H., H. Simonsen, and H. Sфrensen, 1969, Nucl. Phys. A125, 171

Andersen, H. H., J. F. Bak, H. Knudsen, and B. R. Nielsen, 1977, Phys. Rev. A 16, 1929

Andersen, H. H., and B. R. Nielsen, 1981, Nucl. Inst. Meth. 191, 475

Andersen, H. H., and J. F. Zlegler, 1977, "Hydrogen stopping powers and ranges in all elements", Pergamon Press, New York

Anholt, R., 1979, Phys. Rev. A 19, 1004

Anthony, J. M., and W. A. Lanford, 1982, Phys. Rev. A. 25, 1868

Arnau, A., M. Penalba, P. M. Echenique, F. Flores and R. H. Ritchie, 1990, Phys. Rev. Lett. 65, 1024.

Bader, M., R. E. Pixley, F. S. Mozer and W. Whaling, 1956, Phys. Rev. 103,32

Bakker, C. J. and E. Segre, 1951, Phys. Rev. 81, 489

Barkas, W. H. and S. von Friesen, 1961, Nuovo. Cim. Suppl. 19, 41 Barkyoumb, J. H., and D. Y. Smith, 1990, Phys. Rev. A@41, 4863 Basbas, G., 1984, Nucl. Inst. Meth. B 4, 227

Bearden, J. F., and A. F. Burr, 1967, Rev. Mod. Phys. 39, 125 
Berger, M. J., and S. Seltzer, 1964, "Multiple-scattering corrections for proton range measurements", p. 69 in "Studies in penetration of charged particles in matter", Nat. Acad. Sc1. Nat. Res. Council Publication 1133

Bethe, H., 1930, Ann. Phys. 5, 325

Blchsel, H., R. F. Mozley, and W. A. Aron, 1957, Phys. Rev. 105, 1788

Bichsel, H., and E. A. Uehling, 1960, Phys. Rev. 119, 1670

Blchsel, H., 1960, Phys. Rev. 120, 1012

B1chsel, H., 1961, "Higher shell corrections in stopping power", Technical Report No. 3, Physics Dept., Univ. Southern Cal.

B1chsel, H., 1964, "A critical review of experimental stopplng power and range data", p. 17 in "Studies in penetration of charged particles in matter", Nat. Acad. Sci. - Nat. Res. Council Publication 1133

Blchsel, H, and Tschalyr, $\mathrm{Ch}, 1966$; measurements were made for Cu, Ge, Mo, Pt and $\mathrm{Au}$, but were not published because the theory was not satisfactory

Bichsel, H., 1967, "A FORTRAN program for the calculation of the energy loss of heavy charged particles" UCRL-17538

Bichsel, H., and N. Laulainen, 1971, Bull. Am. Phys. SoC. II 16, 842. The paper describing this study has never been published. stopping power, shell corrections and I-values were calculated.

Bichsel, H., 1972, "Passage of Charged Particles Through Matter", ch. $8 d$ in Amex. Inst. Phys. Handbook, $3^{\text {ld }}$ ed., D. E. Gray, ed. (MCGraw H111)

Bichsel, H., and I E Porter, 1982, Phys. Rev. A 25, 2499

Bichsel, H, 1983, Phys Rev A 28, 1147

Bichsel, H., 1987, "Stopping power of L-shell electrons for heavy charged particles", unpublished.

B1chsel, H., 1988, Rev. Mod. Phys.,60,663

Bichsel, Hans, and T. Hiraoka, 1989, Int. J.Quant. Chem. 23, 565 Bichsel, H., 1990, Phys. Rev. A 1,3642 . 
R. Blmbot, S. Della Negra, D. Gardes, H. Gauvin, A. Fleury, and F. Hubert, 1978, Nucl Inst Meth. 153, 161.

R. Bimbot, H. Gauvin, I. Orliange, R. Anne, G. Bastin, and $F$. Hubert, 1986, Nucl Inst Meth. B17, 1.

Bloch, F., 1933, Ann. Phys. 5.Folge 16, 285

Bloembergen, N. and P. J. van Heerden, 1951, Phys. Rev. 83, 561

Bonderup, E., 1967, Dan. Mat. Eys. Medd. 35, No. 17

Borders, JA, 1974, Rad Eff 21, 165

Burkig, V. C. and K. R. Mackenzie, 1957, Phys. Rev. 106, 848

Chu, W. K., and D. Powers, 1972, Phys. Lett. 40A, 23

Chu, W. K., J. F. Zlegler, I. V. Mitchell and W. D. Mackintosh, 1973, Appl. Phys. Lett. 22, 437

Chumanov, 1979, Phys stat Solidi as3, 51

Clement1, E., D. I. Raimond1, and W. P. Reinhardt, 1963, J. Chem. Phys. 47,1300

Cohen, D. D., and M. Harrigan, 1985, Atomic Data and Nucl. Data Tables 33,255

Datz, S., J. Gomez del Campo, P. F. Dittner, P. D. Miller, and J.A. Biggerstaff, 1977, Phys. Rev. Lett. 38, 1145

Dehmer, J. L., M. Inokuti and R. P. Saxon, 1975, Phys Rev A 12, 102 Fano, U., 1963, Ann. Rev. Nucl. Sci. 13, 1.

Fontel1, A. and M. Luomajurvi, 1979, Phys Rev 19, 159

Gauvin, H., R. Bimbot, J. Herault, R. Anne, G. Bastin and F. Hubert, 1987, Nucl Inst Meth B 28191

Green, D. W., J. N. Cooper, and J. C. Harris, 1955, Phys. Rev. 98, 466

Hirschfelder, J. O., and J. I. Magee, 1948, Phys. Rev. 73, 207

ICRU, 1984, "Stopping powers for electrons and positrons", Report 37. International Commission on Radiation Units and Measurements, 7910 Woodmont Ave, Bethesda MD 20814. 
Ishiwari, R., N. Shiom1, S. Shira1, T. Ohata and Y. Uemura, 1971, Bul1. Inst. Chem. Res., Kyoto Univ. 49, 403.

Ishiwari, R., N. Shiomi, and S. Shirai, 1977, Bull. Inst. Chem. Res., Kyoto Univ. 55, 60.

Ishiwari, R., N. Shiomi, T. Kinoshita, and F. Yasue, 1977, Bull. Inst. Chem. Res., Kyoto Univ. 55, 68.

Ishiwari, R., N. Shiomi, and N. Sakamoto, 1978, Bull. Inst. Chem. Res., Kyoto Univ. 56, 47.

Ishiwar1, R., N. Shiom1-Tsuda and N. Sakamoto, 1988, Nucl. Instr. Meth. B31, 503 .

Ishiwar1, R., N. Shiomi and N. Sakamoto, 1984, Nucl. Instr. Meth. B 2, 141

Jann1, J. F., 1982, Atomic Data and Nucl. Data Tables 27, 147

Jhanwar, B. I., Wm. J. Meath and J. C. F. MacDonald, 1983, Rad. Res. 96,20

Johnson, R. E., and M. Inokut1, 1983, Comments At. Mol. Phys. 14, 19

Khandelwal, G.S., 1968, Nucl. Phys. A116, 97

H. Knudsen, H. H. Anderssen, and V. Martini, 1980, Nucl Inst Meth 168,41

Kuldeep and A. K. Jain, 1985, Nucl Inst Meth B9, 259

Langley, R. A. and R. S. Blewer, 1976, Nucl. Instr. Meth. 132, 109

Leung, P. T., M. L. Rustgi, and S. A. T. Long, 1986, Phys. Rev. A 33,2328

Lew1s, H. W., 1952, Phys. Rev. 85, 20

Iiberman, D. A., J. T. Waber, and D. T. Cromer, 1965, Phys. Rev. 137, A27

Liberman, D. A., D. T. Cromer, and J. T. Waber, 1971, Computer Phys. Comm. 2, 107

Lin, W. K., H. G. Olson and D. Powers, 1973, Phys. Rev. B 8, 1881 
Lin, w. K., S. Matteson and D. Powers, 1974, Phys. Rev. B 10, 3746 Lindhard, J., and A. Winther, 1964, Mat. Fys. Medd. Dan. V1d. Selsk. 34, no. 4

Luomajärvi, M., 1979, Rad. Effects. 40, 173

Mather, R. and E. Segre, 1951, Phys. Rev. 84, 191

Matteson, S., J. M. Harris, R. Pretorius, and M-A. Nicolet, 1978, Nucl. Inst. Meth. 149, 163

Nakano, G. H., K. R. Mackenzie and H. Bichsel, 1963, Phys. Rev. 132,291

Nielsen, L. P., 1961, Mat. Fys. Medd. Dan. Vid. Selsk. 33, No. 6

J. C. Oberlin, A. Amokrane, H. Beaumevieille, Y. Le Chalony, R. Perrier de la Bathle, and J. P. Stoquert, 1980, Rad Effects 46, 249

J. C. Oberlin, A. Amokrane, H. Beaumevieille, J. P. Stoquert, and R. Perrier de la Bathie, 1982, J. Physique 43, 485

Porter, I. E., and S. R. Bryan, 1984, Rad. Res. 97, 25; also Nucl. Inst. Meth. 178, 227 (1980)

Raether, H., 1980, "Excitation of Plasmons and Interband Transitions by Electrons", Springer Tracts in Modern Physics, Springer (Berlin, Heldelberg, New York)

Rustgi, M. L., P.T. Leung, and S.A.T. Long, 1988, Phys. Rev. A 37,1775

Sakamoto, N., H. Ogawa, M. Mannami, K. Kimura, Y. Susuki, M. Hasegawa, I. Katayama, T. Noro, and H. Ikegami, 1989, Res. Center for Nucl Phys., Osaka Univ., Annual Report 1988, 117.

Sakamoto, N., N. Shiom1, H. Ogawa, and R. Ishiwar1, 1986, Nucl. Inst. Meth. B13, 115 .

Santry, D. C., and R. D. Werner, 1979, Nucl. Meth. Inst. 159, 523 Santry, D. C., and R. D. Werner, 1980, Nucl. Meth. Inst. 178, 531 Santry, D. C., and R. D. Werner, 1981, Nucl. Meth. Inst. 185, 517 , and 188,211 
Santry, D. C., and R. D. Werner, 1984, Nucl. Meth. Inst. B1, 13

Schwab, Th, H. Gelssel, P. Armbruster, A. Gillibert, W. Mittig, R. E. Olson, K. B. Winterbon, H. Wollnik, and G. Mtnzenberg, 1989, Gesellschaft fur Schwerionenforschung, Preprint GSI-89-79.

Semrad, D., 1990, private communication.

Sh1les, E., T. Sasak1, M. Inokut1, and D. Y. Sm1th, 1980, Phys. Rev. A 22, 1612

Shlomi, N., N. Sakamoto, K. Shima, T. Ishihara, K. Michikawa, S. Naga1, and R. Ish1war1, 1986, Nucl. Inst. Meth. B13, 107

E. I. Sirotinin, A. F. Tulinov, V. A. Khodyrev, and V. N. Mizgulin, 1984, Nucl Inst Meth B4, 337

Sonett, C. P., and K. R. Mackenzie, 1955, Phys. Rev. 100, 734

Sфrensen H. and H. H. Andersen, 1973, Phys. Rev. B 8, 1854

Sternheimer, R. M., S. T. Seltzer, and M. J. Berger, 1982, Phys. Rev. B 26, 6067, and Atomic Data and Nucl Data Tables, 1984, 30, 261

Takahash1, T., Y. Awaya, T. Tonuma, H. Kumaga1, K. Izumo, M. N1shida, A. Hitachi, A. Hashizume, S. Uch1yama and T. Doke, 1983, Phys. Rev. A 27, 1360

Teasdale, J. G., 1949, "The relative stopping power of metals for 12 MeV protons", Tech. Report No. 3, UCLA, Dec. 20

Tschalur, C., 1967, "Energy loss of protons with energies up to 30 MeV in different materials", dissertation, Univ. Southern Calif.

Tschaldy, C., and H. Bichsel, 1968, Phys. Rev. 195, 476

Tschalar, C., 1968, Nucl. Inst. Meth. 64, 237

Vasilevsky, I. M. and Yu. D. Prokoshkin, 1967, Sov. J. Nucl. Phys. 4, 390

Vasilevsky, I. M., I. I. Karpov, V. I. Petrushkin and Yu. D. Prokoshkin, 1969, Sov. J. Nucl. Phys. 9, 583

walske, M. C., 1952, Phys. Rev. 88, 1283

Walske, M. C., 1956, Phys. Rev. 101, 940 
Williamson, C. F., J.-P. Boujot, and J. Picard, 1966, "Tables of range and stopping power for charged particles of energy 0.05 to 500 MeV", Rapport CEA-R 3042, Centre d'Etudes Nucleaires de Saclay

Zeiss, G. D., Wm. J. Meath, J. C. F. MacDonald and D. J. Dawson, 1977, Rad. Res. 70, 284

Zlegler, J. F., 1977, "Hellum stopping powers and ranges for all elemental matter", Pergamon Press, New York. In Table 1 (p.55) of this ref., the values of $S_{e}$ for $z>72$ and for $10<E / M e v \leq 30$ seem to be too small by up to $15 \%$. 
TABLE I. Values of Bloch parameters $b=I / Z$ from various sources, and related quantities (section IIB): average experimental plasmon energies, $h f_{v}$ and plasma energies $h f, a l l$ in ev. $b_{I}$ was calculated for atoms with a local density model, $b$ is the experimental value from Table $V$ and Fig. 5; and $b_{S}$ was calculated from ionization energies. Values used in other tabulations are: $b_{J}$ (Janni, 1982); $b_{A}$ (Andersen and Zlegler, 1977); b (ICRU, 1984). They differ from be partly because different shell corrections and different experimental data sets were used, partly because different assumptions about the dependence on $\mathrm{Z}$ were used.

$\mathrm{b}_{\mathrm{S}}$

$\mathrm{b}_{\mathrm{J}}$

$\mathrm{b}_{\mathrm{A}}$

$b_{I}$

La -45.98 .5$

-
$-\quad 48.2$

8.6

8.32

11.8

9.75

8.42

8.8

$58 \mathrm{Ce}$

- 48.5

8.67

8.76

9.75

8.5

8.8

59 Pr

- 50.6

9.04

8.64

11.2

9.76

8.59

9.1

$62 \mathrm{Sm}$

- 51.5

9.08

9.05

10.0

9.78

8.84

9.78

66

67

67 H०

53.7
$-\quad 54.5$

9.4

8.83

9.0

9.27

8.81

9.2

68

70

\section{2}

73

7

77

78

79 Au 24

$82 \mathrm{~Pb} \quad 1$

- 54.5

9.36

9.17

9.1

9.8

9.09

9.8

9.8
$-\quad 9.8$

9.55

- 55.6

9.6

9.56

8.6

9.11

9.3

9.8

- 48.3

9.65

9.66

7.6

9.82

9.41

9.7

- 66.2

9.76

9.32

- 74.6

9.78

10.05

$25 \quad 80.3$

9.8

10.53

$-$

9.83

9.46

9.82

4 W

$-\quad 86.5$

9.87

10.23

23

84.2

9.96

10.08

4

80.2

10

83 B1 18

61.1

9.79

10

9.2

10.91

9.47

9.83

$9.6 \quad 10.17$

9.37

9.8

$-\quad 9.93$

9.36

9.8

$9.8 \quad 10.58$

9.55

9.8

$9.9 \quad 10.21$

9.73

10.1

$90 \mathrm{Th}$

56.9

9.71

9.5

10.7

9.99

9.56

10

8.98

9.06

8.51

92 U

61.3

9.16

9.09

$-$

9.87

9.26

10

14

8.18

9.22

9.9

14

9.56

9.17

9.4

9.7 
TABLE II. Parameters used for the calculation of shell corrections for the $I-$ and M-shells for some heavy elements. $\mathrm{n}_{\nu}$ is the number of electrons in each subshell. The total number of electrons included in these shells is 26 . In the first line for each element, the value of the atomic unit for each subshell, defined by $\epsilon \nu=R Y \cdot z_{\nu}^{2}$, Eq. (4a), is given in $\mathrm{keV}$. In the second line, the lonization energy is given in atomic units, $W_{m}=J_{\nu} / \epsilon_{\nu}$, where $J_{\nu}$ is the measured lonization energy found in Bearden and Burr (1967).

\begin{tabular}{|c|c|c|c|c|c|c|c|c|}
\hline shell & $I_{I}$ & $I_{I I}$ & $I_{I I I}$ & $\mathrm{M}_{I}$ & $M_{I I}$ & ${ }^{M_{I I I}}$ & $M_{I V}$ & $\mathrm{M}_{\mathrm{V}}$ \\
\hline $\begin{array}{l}n \nu \\
\text { elemes }\end{array}$ & 2 & 2 & 4 & 2 & 2 & 4 & 4 & 6 \\
\hline La & 23.94 & 37.91 & 37.91 & 19.57 & 19.78 & 19.78 & 25.22 & 25.22 \\
\hline 57 & 0.262 & 0.155 & 0.145 & 0.07 & 0.061 & 0.057 & 0.034 & 0.033 \\
\hline Gd & 30.32 & 48.48 & 48.48 & 25.98 & 26.51 & 26.51 & 34.38 & 34.38 \\
\hline 64 & 0.276 & 0.164 & 0.149 & 0.072 & 0.064 & 0.058 & 0.035 & 0.034 \\
\hline Ta & 39.55 & 63.97 & 63.97 & 35.5 & 36.49 & 36.49 & 48.05 & 48.05 \\
\hline 73 & 0.295 & 0.174 & 0.154 & 0.076 & 0.068 & 0.06 & 0.037 & 0.036 \\
\hline Au & 46.34 & 75.51 & 75.51 & 42.29 & 43.73 & 43.73 & 58.36 & 58.36 \\
\hline 79 & 0.31 & 0.182 & 0.158 & 0.081 & 0.072 & 0.063 & 0.039 & 0.038 \\
\hline $\mathrm{Pb}$ & 49.66 & 81.63 & 81.63 & 45.99 & 47.58 & 47.58 & 63.9 & 63.9 \\
\hline 82 & 0.319 & 0.186 & 0.16 & 0.084 & 0.075 & 0.064 & 0.04 & 0.039 \\
\hline U & 60.21 & 99.65 & 99.65 & 56 & 58.49 & 58.49 & 80.4 & 80.4 \\
\hline 2 & 0.361 & 0.21 & 0.172 & 0.096 & 0.085 & 0.079 & 0.045 & 0.044 \\
\hline
\end{tabular}


TABLE III. Ionization energies $J_{\nu}$ (Bearden and Burr, 1961) and horizontal scaling factors $\mathrm{H}_{1}$ and $\mathrm{H}_{2}$ for the calculation, Eq. (5), of the shell corrections $C_{N_{1}}$ the average value for the 8 electrons in shells $N_{I}$ to $N_{I I I)}$ ) and $C_{N 2}$ (for the 10 electrons in shells $\mathrm{N}_{I V}$ and $\mathrm{N}_{V}$ ). Values of $\mathrm{H}_{1}$ and $\mathrm{H}_{2}$ are defined by the average value of the ratios $\mathrm{J}_{M V} / \mathrm{J}_{\mathrm{N} \nu}$, weighted with number $n_{\nu}$ of electrons in each subshell.

\begin{tabular}{|c|c|c|c|c|c|c|c|c|}
\hline shell & $M_{V}$ & $N_{I}$ & $\mathbb{N}_{I I}$ & $\mathrm{~N}_{\text {III }}$ & ${ }^{\mathrm{N}}$ IV & $N_{V}$ & $\mathrm{H}_{1}$ & $\mathrm{H}_{2}$ \\
\hline $\mathrm{n}_{\nu}$ & 6 & 2 & 2 & 4 & 4 & 6 & & \\
\hline \multicolumn{3}{|c|}{ element } & \multicolumn{3}{|c|}{$J_{\nu}(e v)$} & & & \\
\hline $\mathrm{La}$ & 832 & 270 & 206 & 191 & 99 & 99 & 3.96 & 8.4 \\
\hline Gd & 1985 & 376 & 289 & 271 & 141 & 141 & 4 & 8.4 \\
\hline Ex & 1409 & 449 & 366 & 320 & 177 & 168 & 3.94 & 8.22 \\
\hline $\mathrm{Ta}$ & 1735 & 566 & 465 & 404 & 241 & 229 & 3.84 & 7.43 \\
\hline Au & 22.06 & 759 & 644 & 545 & 352 & 334 & 3.6 & 6.47 \\
\hline $\mathrm{Pb}$ & 2484 & 894 & 764 & 644 & 435 & 413 & 3.43 & 5.89 \\
\hline 89 & 3552 & 9449 & 1273 & 1045 & 780 & 738 & 3.01 & 4.71 \\
\hline
\end{tabular}


TABLE IV. Parameters $\mathrm{V}_{1}, \mathrm{~V}_{2}, \mathrm{H}_{3}$ and $\mathrm{V}_{3}$ for local best fits to the average data set for protons in gold, obtained in a four parameter grid search. $\mathrm{H}_{1}=3.6$ and $\mathrm{H}_{2}=6.47$ are given in Table II. $\sigma^{2}$ is defined in Eq. $(10 a), \sigma^{2}$ in Eq. (12), and I = $\exp \left(Y_{Z}\right) \quad[E q \cdot 2(10)]$. A local best fit is defined be a local minimum of $\sigma^{2}$ in the four dimensional space defined by $V_{1}, V_{2}$ ' $\mathrm{V}_{3}$ and $\mathrm{H}_{3}$. Note that the smallest values of $\sigma$ do not necessarily pccur at the same grid-point as the ${ }^{x}$ smallest values of $\sigma^{2}$. This is because of the nonlinear relation between $\ell n I$ and $S$.

$\begin{array}{llllcll}V_{1} & V_{2} & H_{3} & V_{3} & \sigma^{2} & I_{a} / \mathrm{eV} & \sigma_{\mathrm{x}}{ }^{8} \\ 1.3 & 1.1 & 12.8 & 1.35 & 0.01494 & 792 & 0.1525 \\ 1.3 & 1.15 & 13 . & 1.35 & 0.01466 & 791.4 & 0.1555 \\ 1.3 & 1.2 & 13 . & 1.35 & 0.01511 & 790.3 & 0.1602 \\ 1.3 & 1.25 & 13.2 & 1.35 & 0.01631 & 789.7 & 0.1686 \\ 1.3 & 1.3 & 13.4 & 1.3 & 0.01645 & 790.9 & 0.1678 \\ 1.25 & 1.35 & 12.8 & 1.3 & 0.01498 & 791.3 & 0.1633 \\ 1.25 & 1.4 & 13 . & 1.3 & 0.01429 & 790.7 & 0.1571 \\ 1.25 & 1.45 & 13.2 & 1.3 & 0.01459 & 790 & 0.1613 \\ 1.25 & 1.5 & 13.4 & 1.3 & 0.01579 & 789.3 & 0.1737 \\ 1.2 & 1.55 & 12.8 & 1.25 & 0.01674 & 791.7 & 0.1684 \\ 1.2 & 1.6 & 13 . & 1.25 & 0.01513 & 791 & 0.159 \\ 1.2 & 1.65 & 13.2 & 1.25 & 0.01448 & 790.3 & 0.1588 \\ 1.2 & 1.7 & 13.2 & 1.25 & 0.01447 & 789.3 & 0.1677 \\ 1.2 & 1.75 & 13.4 & 1.25 & 0.01532 & 788.6 & 0.172 \\ 1.2 & 1.8 & 13.6 & 1.25 & 0.01696 & 787.9 & 0.1822 \\ 1.15 & 1.85 & 13.9 & 1.2 & 0.01541 & 790.3 & 0.1745 \\ 1.95 & 13.4 & 1.2 & 0.01433 & 788.9 & 0.1678 \\ 1.3 & 13.6 & 1.2 & 0.01503 & 788.2 & 0.174\end{array}$


Table V. Symbols used for plotting data in Figs. 3-13

Reference

symbol

Oberlin (1980, 1982), Luomajarvi (1979)

$\times$

Bader (1956), Borders (1974)

$\diamond$

Langley (1976), Santry (1984)

Knudsen (1980), Green (1955), Chumanov (1979)

Nara

צ

UCLA, Lin (1973)

里

DK, Fontell (1979)

X

Semrad (1990), Chu (1973)

米

Sirotinin (1984), Kuldeep (1985)

Nara: Ish1wari (1984, 1988), Sakamoto (1986), Shiomi (1986)

UCLA: Teasdale(1949), Sonett(1955), Burkig(1957), Nakano(1963)

DK: S申rensen (1973), Andersen (1967, 1969, 1981) 
TABLE VI. Best fit values of $\mathrm{H}_{3}$ and $\mathrm{V}_{3}$ for $57 \leq \mathrm{Z} \leq 73$, obtained in a two parameter search for protons with $\mathrm{T}>0.3 \mathrm{MeV}$ and $\alpha$ with $T>1.6 \mathrm{MeV}$ with $V_{1}=1.25$ and $V_{2}=1.4$, and $H_{1}$ and $H_{2}$ from Table III. $\sigma$ is defined by Eq. \{12), I by Eq. (10b\}. If $\mathrm{V}_{3}=0, \mathrm{H}_{3}$ is 1 ndeterminate. The experiméntal errors $\sigma$ are those glven by the authors (for some, an average valie 15 given). Authors: A: Andersen et al. (1969); B: Bader et al. (1956); Bo: Borders (1974); C: Chu et al. (1973); G: Green et al. (1955); K: Knudsen et al. (1980); I: Luomajurvi (1979); La: Langley and Blewer (1976); N: Ishiwari et al. (1988); 0: Oberlin et al. (1980, 1982); P: Iin et al. (1973, 1974); S: Sirotinin et al. (1984); U: Teasdale (1949), Sonett and Mackenzie (1955), Burkig and Mackenzie (1957) and Nakano et al. (1963).

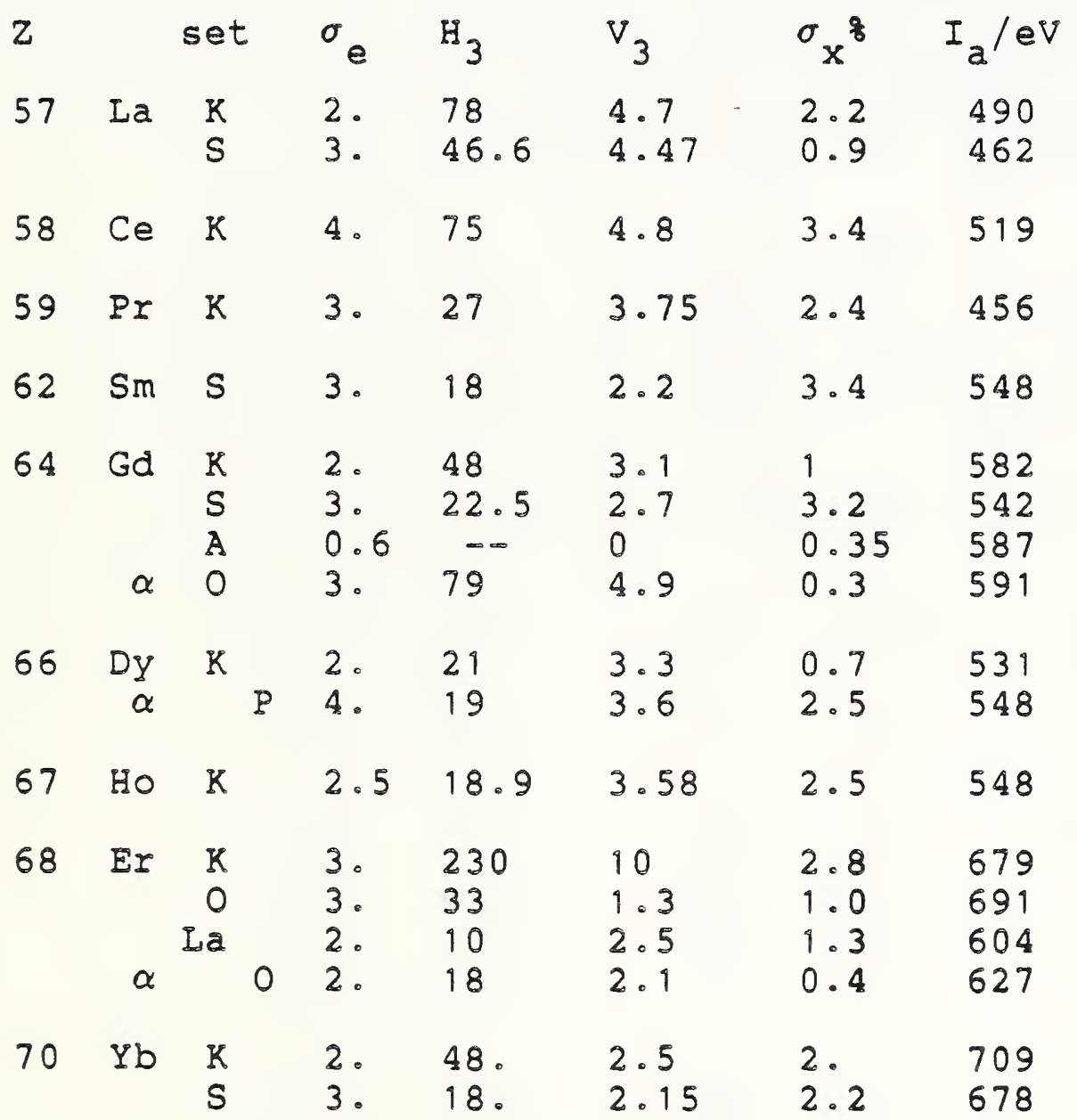

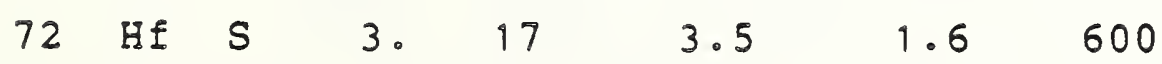




\begin{tabular}{|c|c|c|c|c|c|}
\hline $73 \mathrm{Ta}$ & $\begin{array}{l}B \\
L \\
A \\
S \\
U \\
N \\
P\end{array}$ & $\begin{array}{l}3 . \\
2.7 \\
0.6 \\
3 . \\
- \\
0.3 \\
4 .\end{array}$ & $\begin{array}{c}10 . \\
16 . \\
10 . \\
15.5 \\
- \\
14.5 \\
21.5\end{array}$ & $\begin{array}{l}0.6 \\
1.3 \\
0.6 \\
2.2 \\
0.2 \\
0.7 \\
1.5\end{array}$ & $\begin{array}{l}0.3 \\
0.6 \\
0.6 \\
1.4 \\
1.2 \\
0.1 \\
0.1\end{array}$ \\
\hline
\end{tabular}

TABLE VIa. Best fit values of $V_{3}$ for some $Z$ obtained in a one parameter search for protons with $\mathrm{T} \geq 0.3 \mathrm{MeV}, \alpha$ with $\mathrm{T} \geq 1.6 \mathrm{MeV}$ with $V_{1}=1.25$ and $V_{2}=1.4, H_{1}$ and $H_{2}$ from Table II and $\mathrm{H}_{3}=50$ for $\mathrm{Z}<60, \mathrm{H}_{3}=25$ for $60 \leq \mathrm{Z} \leq 72, \mathrm{H}_{3}=13$ for $\mathrm{Z} \geq 73$. The values of $\mathrm{V}_{3}$ are shown th F1g. 4. $\sigma$ and ${ }^{3}$ are given. In the last two cols., average I-values, $\mathrm{Xq}_{\mathrm{Eq}}(18 \mathrm{~b})$ are given, for $V_{3}=3.85$ for $\mathrm{z}<60, \mathrm{~V}_{3}=2.3$ for $60<\mathrm{Z} \leq 72, \mathrm{~V}_{3}=(\mathrm{z}-46) / 25$ for $\mathrm{z} \geq 73$. $\sigma_{\mathrm{x}}$ is also shown. The latter $I_{a}$ are also shown in Fig. 5 .

\begin{tabular}{|c|c|c|c|c|c|c|}
\hline Z & set & $v_{3}$ & $\sigma_{x}^{z}$ & $I_{a} / e V$ & $\sigma_{\mathrm{x}}$ & $I_{a} / e V$ \\
\hline 57 & $\begin{array}{ll}\text { La } & K \\
& \mathrm{~S} \\
\alpha & \mathrm{P} \\
\alpha & \mathrm{K}\end{array}$ & $\begin{array}{l}3.25 \\
4.8 \\
4 \\
6.9\end{array}$ & $\begin{array}{l}2.1 \\
0.9 \\
0 . \\
0 .\end{array}$ & $\begin{array}{l}484 \\
462 \\
460 \\
433\end{array}$ & $\begin{array}{l}3.1 \\
2.0 \\
0.1 \\
2.1\end{array}$ & $\begin{array}{l}473 \\
472 \\
463 \\
487\end{array}$ \\
\hline 58 & $\begin{array}{ll}\mathrm{Ce} & \mathrm{K} \\
\alpha & \mathrm{K}\end{array}$ & 3.05 & 3.4 & 519 & $\begin{array}{l}3.6 \\
2.4\end{array}$ & $\begin{array}{l}507 \\
590\end{array}$ \\
\hline 59 & $\begin{aligned} \text { Pr } & K \\
\alpha & K\end{aligned}$ & $\begin{array}{l}4.4 \\
7.6\end{array}$ & $\begin{array}{l}2.9 \\
0\end{array}$ & $\begin{array}{l}499 \\
451\end{array}$ & $\begin{array}{l}3.9 \\
2.9\end{array}$ & $\begin{array}{l}502 \\
528\end{array}$ \\
\hline 62 & $\mathrm{Sm}$ & 2.4 & 3.6 & 558 & 3.6 & 561 \\
\hline 64 & $\begin{array}{rr}\text { Gd } & K \\
& \mathrm{~S} \\
& \mathrm{~A} \\
\alpha & 0 \\
\alpha & \mathrm{K} \\
\alpha & \mathrm{C}\end{array}$ & $\begin{array}{l}2.45 \\
2.85 \\
0 \\
2.25 \\
1.8\end{array}$ & $\begin{array}{l}1.6 \\
3.2 \\
0.35 \\
0.4 \\
0 .\end{array}$ & $\begin{array}{l}555 \\
543 \\
587 \\
560 \\
600\end{array}$ & $\begin{array}{l}1.8 \\
3.8 \\
0.8 \\
0.4 \\
0.5\end{array}$ & $\begin{array}{l}561 \\
560 \\
576 \\
558 \\
573 \\
548\end{array}$ \\
\hline 66 & $\begin{aligned} \text { Dy } & \mathrm{K} \\
\alpha & \mathrm{P} \\
\alpha & \mathrm{K}\end{aligned}$ & $\begin{array}{l}2.75 \\
2.2 \\
2.6\end{array}$ & $\begin{array}{l}9.8 \\
0.9 \\
0 .\end{array}$ & $\begin{array}{l}567 \\
609 \\
605\end{array}$ & $\begin{array}{l}1.9 \\
0.1 \\
0.4\end{array}$ & $\begin{array}{l}588 \\
604 \\
622\end{array}$ \\
\hline 67 & Ho $\begin{aligned} & K \\
& \alpha K\end{aligned}$ & $\begin{array}{l}3.1 \\
1.3\end{array}$ & $\begin{array}{l}3.3 \\
0 .\end{array}$ & $\begin{array}{l}597 \\
719\end{array}$ & $\begin{array}{l}3.3 \\
1.9\end{array}$ & $\begin{array}{l}632 \\
655\end{array}$ \\
\hline
\end{tabular}


$\begin{array}{lll}68 & \text { Er } K \\ 0\end{array}$
La 2.2
$\alpha \mathrm{K}$
$\begin{array}{lll}\alpha & 0 & 1.8\end{array}$
$\alpha$ La 2.8

$\begin{array}{llll}70 & \text { Yb } K & 2.35\end{array}$

$\begin{array}{lll} & S & 2 \\ \alpha & K & 0 .\end{array}$

72 He S 3.25

$$
\alpha C
$$

$73 \mathrm{Ta}$

$\begin{array}{rll}\text { a B } & 1.1 \\ \text { I } & 1.6 \\ \text { A } & 0.8 \\ \text { S } & 2.3 \\ U & 0 \\ & N & 0.5 \\ \alpha & P & 0 .\end{array}$

$82 \mathrm{~Pb} B$

$\begin{array}{cc}B & 2.0 \\ G & 2.9 \\ A & 1.4 \\ S & 1.6 \\ U & 0 \\ N & 1.5\end{array}$

$\alpha$ Bo
4.3

1.4

2 .

1.5

0.5

0

$\begin{array}{ll}0.8 & 665 \\ 3 . & 698 \\ 2.7 & 860\end{array}$

3.8

0.5

0.4

0.05

2.9

1.2

0.1

0.5

630

751

716

712

697

741

738

884

$1.0 \quad 709$

1. 7

0.1

3

0.8

0.1

0.9

652

781

782

832

776

850
4.1 620
2.1
650
2. 1
671
2.7
633
0.8
0.5
640
635

$\begin{array}{ll}0.7 & 667 \\ 4.1 & 684 \\ 4.4 & 691\end{array}$

$3.2 \quad 671$

683

$0.5 \quad 752$

$0.8 \quad 751$

$0.2 \quad 707$

$3.7 \quad 760$

$1.3 \quad 735$

$0.1 \quad 733$

$0.7 \quad 787$

$1.3 \quad 743$

$2 \quad 753$

0.12779

$3.0 \quad 794$

1.2 816

$0.1 \quad 776$

1. 792 
TABLE VII. Energy loss measurements in thick absorbers with absolute energy measurements: Bichsel and Tschaldr (1966). Initial energy $T_{1}$ and final energy $T_{f}$ in $M e V$. The experimental absorber thicknesses are $t_{x}=0.5385 \mathrm{~g} / \mathrm{cm}^{2}$ for $P t$, $t_{\mathrm{x}}=0.5034 \mathrm{~g} / \mathrm{cm}^{2}$ for Au. The theoretical absorber thicknesses $t_{t}^{x}\left(\mathrm{~g} / \mathrm{cm}^{2}\right)$ were obtained from ranges calculated with Eq. (8), and $\Delta=\left(t_{1}-t_{t}\right) / t_{t}$. A larger I-value would increase $t_{t}$. For a Iinear regression fit to $\Delta\left(t_{t}\right)$, the statistical fluctuation of $\Delta$ is \pm 0.28 .

\begin{tabular}{|c|c|c|c|c|}
\hline & $T_{1}$ & $\mathrm{~T}_{\mathbf{f}}$ & $t_{t}$ & $\Delta($ \& $)$ \\
\hline Pt & $\begin{array}{l}14.364 \\
14.416 \\
14.538 \\
14.735 \\
14.761 \\
15.258 \\
15.778 \\
16.315 \\
16.811 \\
17.507 \\
18.329 \\
19.198 \\
20.021 \\
20.909 \\
21.961 \\
23.045 \\
24.129 \\
25.243 \\
25.433\end{array}$ & $\begin{array}{r}4.104 \\
4.223 \\
4.477 \\
4.909 \\
4.964 \\
5.952 \\
6.881 \\
7.785 \\
8.585 \\
9.651 \\
10.866 \\
12.068 \\
13.192 \\
14.361 \\
15.703 \\
17.052 \\
18.371 \\
19.726 \\
19.919\end{array}$ & $\begin{array}{l}0.5379 \\
0.5378 \\
0.5380 \\
0.5370 \\
0.5368 \\
0.5354 \\
0.5352 \\
0.5349 \\
0.5343 \\
0.5340 \\
0.5329 \\
0.5335 \\
0.5325 \\
0.5322 \\
0.5322 \\
0.5323 \\
0.5326 \\
0.5308 \\
0.5337\end{array}$ & $\begin{array}{l}0.11 \\
0.13 \\
0.1 \\
0.28 \\
0.31 \\
0.58 \\
0.62 \\
0.68 \\
0.78 \\
0.84 \\
1.06 \\
0.95 \\
1.12 \\
1.19 \\
1.18 \\
1.17 \\
1.11 \\
1.45 \\
0.99\end{array}$ \\
\hline Au & $\begin{array}{l}14.011 \\
14.503 \\
15.004 \\
15.513 \\
16.16 \\
16.821 \\
17.631 \\
18.459 \\
19.306 \\
20.171 \\
21.055 \\
21.957 \\
22.569\end{array}$ & $\begin{array}{c}4.354 \\
5.339 \\
6.252 \\
7.145 \\
8.19 \\
9.204 \\
10.394 \\
11.553 \\
12.719 \\
13.845 \\
14.976 \\
16.117 \\
16.888\end{array}$ & $\begin{array}{l}0.5045 \\
0.5042 \\
0.5041 \\
0.5031 \\
0.5029 \\
0.5026 \\
0.5022 \\
0.5020 \\
0.5005 \\
0.5009 \\
0.5009 \\
0.4999 \\
0.4984\end{array}$ & $\begin{array}{r}-0.22 \\
-0.15 \\
-0.14 \\
0.06 \\
0.09 \\
0.15 \\
0.25 \\
0.27 \\
0.58 \\
0.5 \\
0.5 \\
0.79 \\
1.0\end{array}$ \\
\hline
\end{tabular}


TABLE VIII. Comparison $q^{f}$ calculated, $S_{f}$ and measured stopping power, $S_{x}\left(\mathrm{MeV} \mathrm{cm}^{2} / \mathrm{g}\right)$. The kinetlc energy, $T$, of the particles is given in $\mathrm{MeV}$, the authors experimental accuracy $15 \sigma_{e^{\prime}}$ and $r(z)$ is the relative difference, Eq. (11).

$1^{\text {st }}$ auth part $\mathrm{z}$

$\begin{array}{lll}\text { Sakamoto } & \mathrm{P} & \mathrm{Ta} \\ 1989 & \mathrm{Pt} \\ & \mathrm{Au} \\ & \mathrm{Pb}\end{array}$

$\begin{array}{lll}\text { Chu } & \alpha & \mathrm{Ta} \\ 1973 & & \mathrm{Au} \\ & & \mathrm{Pb}\end{array}$

Santry $\mathrm{He}^{3}$ Au

1981

Santry $\mathrm{He}^{4} \mathrm{AU}$

1980

Santry $\mathrm{He}^{4}$ Au

1979

Santry $\alpha \quad$ Au

1984

Datz

$\stackrel{\mathrm{p}}{\alpha} \mathrm{A}$

II

B

C

$\mathrm{N}$

0

p

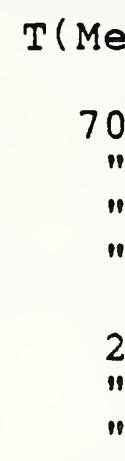

1.0

1.2

1.4

1.6

1.8

2.0

1.0

1.2

1.4

1.6

1.8

2.0

3.08

5.49

3.18

4.78

5.16

5.49

5.8

6

7.69

2
8

18

50

72

98

128

3.5

14

$$
s_{x} \pm \sigma_{e}(z)
$$

$s_{t}$

$r$ \%

$\begin{array}{lll}4.579 \pm 0.7 & 4.618 & 0.9 \\ 4.508 \pm 0.7 & 4.511 & 0.1 \\ 4.491 \pm 0.7 & 4.518 & 0.6 \\ 4.388 \pm 0.7 & 4.469 & 1.9\end{array}$

$$
\begin{aligned}
& 366 \pm 3 \\
& 358 \pm 3 \\
& 363 \pm 3
\end{aligned}
$$

$\begin{array}{rr}378 & 3 \\ 347 & -3 \\ 348 & -4\end{array}$

$377 \pm 5$ \%

363

348

332

315

301

$408 \cdot 8$

$380 \quad 5$

$\begin{array}{ll}357 & 2.6\end{array}$

$338 \quad 2$

$322 \quad 2$

$309 \quad 2.6$

$390 \pm 4$ 응

$454 \quad 16$

$424 \quad 12$

3998

3797

3625

344

331

347

$285 \pm 8$ \%

$228 \pm 6$ \%

290

$223-2.2$

$285 \pm 4$ 응

286

238

230

223

217

214

$189-9$
0.4

$-1.7$

$-2.2$

$-2.2$

$-1.8$

$-3$

$-9$
45.6

185

419.5

1146

1627

2257

2815

2259 


$\begin{array}{lllll}\mathrm{L} 1 & 31.5 & 292 & 311 & 6.7 \\ \mathrm{~B} & 87.5 & 810 & 861 & 6.3\end{array}$

\begin{tabular}{|c|c|c|c|c|c|c|}
\hline $\begin{array}{l}\text { Anthony } \\
1982\end{array}$ & $C$ & $\mathrm{Au}$ & $\begin{array}{l}28.2 \\
33.6 \\
39.6\end{array}$ & $\begin{array}{l}1300 \pm 28 \\
1250 \pm 38 \\
1180 \pm 38\end{array}$ & $\begin{array}{l}1509 \\
1383 \\
1270\end{array}$ & $\begin{array}{l}16 \\
11 \\
8\end{array}$ \\
\hline $\begin{array}{l}\text { Ish1war1 } \\
1971,1977 \\
1978\end{array}$ & $\alpha$ & $\begin{array}{l}\mathrm{Ta} \\
\mathrm{Au}\end{array}$ & $\begin{array}{l}8.05 \\
28.2 \\
28.27 \\
28.21 \\
28.28\end{array}$ & $\begin{array}{ll}199.7 & \pm 0.3 \\
93.46 & \pm 1 \\
93.1 & \pm 0.5 \\
90.13 & \pm 1 \\
91.18 & \pm 0.5\end{array}$ & $\begin{array}{l}193.9 \\
93.43 \\
93.28 \\
90.17 \\
90.04\end{array}$ & $\begin{array}{l}-2.9 \\
0 \\
0.2 \\
0 \\
-1.2\end{array}$ \\
\hline $\begin{array}{l}\text { Takahash1 } \\
1983\end{array}$ & $\begin{array}{l}\alpha \\
C \\
\alpha \\
C\end{array}$ & Au & $\begin{array}{l}20.6 \\
27.63 \\
61.79 \\
82.9 \\
21.65 \\
28.59 \\
64.94 \\
85.78\end{array}$ & $\begin{array}{l}110 \pm 0.7 \\
92.8 \pm 0.75 \\
961 \pm 0.7 \\
839 \pm 0.7 \\
106 \pm 0.9 \\
89.5 \pm 0.9 \\
982 \pm 0.7 \\
814 \pm 0.7\end{array}$ & $\begin{array}{l}109.4 \\
91.35 \\
989 \\
828 \\
105.1 \\
88.47 \\
951 \\
802.6\end{array}$ & $\begin{array}{l}-0.5 \\
-1.6 \\
2.9 \\
-1.3 \\
-0.8 \\
-1.1 \\
-3.2 \\
-1.4\end{array}$ \\
\hline
\end{tabular}

Bimbot 1978

Gauvin 1987

Bimbot 1986
Au

70.24

74.88

75.52

92.64

96.16

96.96

0

$\mathrm{Ta}$

393

417

431

723

762

773

1418

1453

Au

396

421

433

713

754

774

1350

1429

Ar

$\mathrm{Ta}$

$\begin{array}{lll}1720 \pm 3 & 1901 & 10 \\ 1350 \pm 6 & 1835 & 36 \\ 1350 \pm 5 & 1826 & 35 \\ 1560 \pm 4 & 1625 & 4 \\ 1450 \pm 8 & 1589 & 10 \\ 1480 \pm 9 & 1582 & 7\end{array}$

$\begin{array}{llll}646 \pm 1.2 & 649 & 0.5\end{array}$

$620 \pm 1.7 \quad 623 \quad 0.5$

$600 \pm 1.7 \quad 608 \quad 1.3$

$419 \pm 1.4 \quad 419 \quad 0$

$399 \pm 1.8 \quad 404 \quad 1.2$

$400 \pm 2.5 \quad 400 \quad 0$

$263 \pm 1.5 \quad 260-1.1$

$257 \pm 2.3 \quad 255 \quad-0.8$

$616 \pm 1.3 \quad 629 \quad 2.1$

$600 \pm 1.7 \quad 602 \quad 0.3$

$590 \pm 1.7 \quad 591 \quad 0.2$

$412 \pm 1.5 \quad 414 \quad 0.5$

$\begin{array}{llll}391 \pm 1.8 & 398 & 1.8\end{array}$

$390 \pm 2.5 \quad 390 \quad 0$

$263 \pm 1.1 \quad 263 \quad 0$

$259 \pm 1.5 \quad 253 \quad-2.3$

$3050 \pm 1 \quad 3170 \quad 4$

$2920 \pm 3 \quad 3076 \quad 5$

$3080 \pm 4 \quad 3058 \quad-0.7$

$1800 \pm 1.7 \quad 1794 \quad-0.3$ 


\begin{tabular}{|c|c|c|c|c|c|c|c|}
\hline & & & 2342 & 1750 & \pm 2.3 & 1771 & 1.2 \\
\hline & & $A u$ & $\begin{array}{r}935 \\
1027 \\
1059 \\
1073 \\
1532 \\
1653 \\
1718 \\
2157 \\
2301 \\
2356 \\
2957 \\
3028\end{array}$ & $\begin{array}{l}31110 \\
3050 \\
2880 \\
2800 \\
2330 \\
2150 \\
21100 \\
1810 \\
1730 \\
1760 \\
1440 \\
1400\end{array}$ & $\begin{array}{l} \pm 1.3 \\
\pm 1.6 \\
\pm 3 \\
\pm 4 \\
\pm 1 \\
\pm 1.5 \\
\pm 2.4 \\
\pm 2.8 \\
\pm 2.3 \\
\pm 2.8 \\
\pm 1.4 \\
\pm 2.9\end{array}$ & $\begin{array}{l}3268 \\
3067 \\
3004 \\
2978 \\
2329 \\
2209 \\
2151 \\
1834 \\
1753 \\
1725 \\
1472 \\
1448\end{array}$ & $\begin{array}{l}5 \\
0.6 \\
4 \\
6 \\
0 \\
2.7 \\
2.4 \\
1.3 \\
1.3 \\
-2 \\
2.2 \\
3.4\end{array}$ \\
\hline & $\mathrm{Ca}$ & $A u$ & $\begin{array}{l}2919 \\
3010\end{array}$ & $\begin{array}{l}1830 \\
1750\end{array}$ & $\begin{array}{l} \pm 1.1 \\
\pm 2.3\end{array}$ & $\begin{array}{l}1834 \\
1796\end{array}$ & $\begin{array}{l}0.2 \\
2.6\end{array}$ \\
\hline Schwab & Ar & Pt & 2912 & 1366 & \pm 0.6 & 1381 & 1.1 \\
\hline & & $A u$ & $\begin{array}{l}2402 \\
2650 \\
3005\end{array}$ & $\begin{array}{l}1556 \\
1451 \\
1367\end{array}$ & $\begin{array}{l} \pm 0.1 \\
\pm 0.3 \\
\pm 0.8\end{array}$ & $\begin{array}{l}1581 \\
1477 \\
1354\end{array}$ & $\begin{array}{r}1.6 \\
1.8 \\
-1\end{array}$ \\
\hline
\end{tabular}


TABLE IX. Measurements of energy loss relative to Al or Cu. The theoretical values of $S$ for $A l$ and $C u$ are given. The Barkas and von Friesen (1961) data for Al alloy have been converted to pure $\mathrm{Al}_{2}$ The energy $\mathrm{T}$ is the average between $\mathrm{T}_{1}$ and $T_{f}$. $S$ in $\mathrm{MeV} \mathrm{Cm} / g, r$ given by Eq. (11). Theoretical $\mathrm{S}_{t}^{1}$ for $A I$ and $C u$ are given for reference. Barkas data are for pure AI (ICRU 1984).

\begin{tabular}{|c|c|c|c|c|c|c|}
\hline First author & $\mathrm{z}$ & $\mathrm{T} / \mathrm{MeV}$ & $S_{x} \pm c$ & $e^{z}$ & $s_{t}$ & $x^{8}$ \\
\hline $\begin{array}{l}\text { Bakker } \\
\text { rat10 }\end{array}$ & $\begin{array}{l}W \\
\mathrm{~Pb} \\
U \\
\mathrm{~A} \perp / \mathrm{CU}\end{array}$ & $\begin{array}{c}300 \\
" 1 \\
" 1\end{array}$ & $\begin{array}{l}1.874 \\
1.819 \\
1.736 \\
1.143\end{array}$ & $\begin{array}{l} \pm 1 \\
\pm 1 \\
\pm 1 \\
\pm 1\end{array}$ & $\begin{array}{l}1.858 \\
1.827 \\
1.758 \\
1.155\end{array}$ & $\begin{array}{r}-0.9 \\
0.4 \\
1.3 \\
1.9\end{array}$ \\
\hline Barkas & $\mathrm{Pb}$ & $\begin{array}{l}380 \\
530 \\
680\end{array}$ & $\begin{array}{l}1.606 \\
1.391 \\
1.277\end{array}$ & & $\begin{array}{l}1.627 \\
1.419 \\
1.307\end{array}$ & $\begin{array}{l}1 \cdot 3 \\
2 \\
2 \cdot 3\end{array}$ \\
\hline & U & $\begin{array}{l}380 \\
530 \\
680\end{array}$ & $\begin{array}{l}1.548 \\
1.353 \\
1.24\end{array}$ & & $\begin{array}{l}1.567 \\
1.365 \\
1.258\end{array}$ & $\begin{array}{l}1.2 \\
0.9 \\
1.4\end{array}$ \\
\hline & AI & $\begin{array}{l}380 \\
530 \\
680\end{array}$ & $\begin{array}{l}2.415 \\
2.089 \\
1.913\end{array}$ & & $\begin{array}{l}2.451 \\
2.116 \\
1.936\end{array}$ & $\begin{array}{l}1.5 \\
1.3 \\
1.2\end{array}$ \\
\hline & $\mathrm{Cu}$ & $\begin{array}{l}380 \\
530 \\
680\end{array}$ & - & & $\begin{array}{l}2.126 \\
1.837 \\
1.681\end{array}$ & \\
\hline $\begin{array}{l}\text { Vasilevskii } \\
1967\end{array}$ & $\mathrm{~Pb}$ & $\begin{array}{l}173.9 \\
188.5 \\
615 \\
650\end{array}$ & $\begin{array}{l}2.496 \\
2.347 \\
1.345 \\
1.332\end{array}$ & $\begin{array}{l} \pm 0.8 \\
\pm 0.8 \\
\pm 0.8 \\
\pm 1.3\end{array}$ & $\begin{array}{l}2.496 \\
2.376 \\
1.348 \\
1.325\end{array}$ & $\begin{array}{r}0 \\
1.2 \\
0.2 \\
-0.5\end{array}$ \\
\hline & $\mathrm{Cu}$ & $\begin{array}{l}173.9 \\
188.5 \\
615 \\
650\end{array}$ & $\begin{array}{l}3.332 \\
3.142 \\
1.765 \\
1.734\end{array}$ & $\begin{array}{l} \pm 0.5 \\
\pm 0.5 \\
\pm 0.6 \\
\pm 1.0\end{array}$ & $\begin{array}{l}3.32 \\
3.154 \\
1.739 \\
1.706\end{array}$ & $\begin{array}{r}-0.3 \\
0.4 \\
-1.5 \\
-1.6\end{array}$ \\
\hline $\begin{array}{l}\text { Vasilevski1 } \\
1969\end{array}$ & $\mathrm{~Pb}$ & $\begin{array}{l}110 \\
300 \\
420 \\
600\end{array}$ & $\begin{array}{l}3.314 \\
1.804 \\
1.531 \\
1.343\end{array}$ & $\begin{array}{l} \pm 0.8 \\
\pm 0.6 \\
\pm 0.6 \\
\pm 0.5\end{array}$ & $\begin{array}{l}3.364 \\
1.827 \\
1.557 \\
1.359\end{array}$ & $\begin{array}{l}1.5 \\
1.3 \\
1.7 \\
1.2\end{array}$ \\
\hline & $\mathrm{Cu}$ & $\begin{array}{l}110 \\
300 \\
420 \\
600\end{array}$ & $\begin{array}{l}4.51 \\
2.405 \\
2.029 \\
1.761\end{array}$ & $\begin{array}{l} \pm 0.8 \\
\pm 0.6 \\
\pm 0.6 \\
\pm 0.5\end{array}$ & $\begin{array}{l}4.53 \\
2.399 \\
2.028 \\
1.754\end{array}$ & $\begin{array}{c}0.4 \\
-0.2 \\
0 \\
-0.4\end{array}$ \\
\hline
\end{tabular}


TABLE $X$. Comparison of experimental ranges $R_{x}$ to theoretical ranges $R_{t}\left(\mathrm{~g} / \mathrm{cm}_{2}\right)$. The kinetic energy of the incident particles is $T 2(\mathrm{MeV}), \Delta R=R_{-}-R_{t}$. Except for the Bloembergen and van Heerden (1951) data, the experimental ranges have been corrected for multiple scattering.

\begin{tabular}{|c|c|c|c|c|c|}
\hline $1^{\text {st }}$ author & & $\mathrm{T}(\mathrm{MeV})$ & $\mathrm{R}_{\mathrm{x}} \pm \sigma \mathrm{e}^{z}$ & $R_{t}$ & $\Delta R / R \quad \%$ \\
\hline $\begin{array}{l}\text { Bichsel } \\
1957\end{array}$ & $A u$ & $\begin{array}{r}9.698 \\
17.549\end{array}$ & $\begin{array}{l}0.3316 \\
0.8685\end{array}$ & $\begin{array}{l}0.3324 \\
0.8667\end{array}$ & $\begin{array}{c}-0.25 \\
0.2\end{array}$ \\
\hline $\begin{array}{l}\text { Bloembergen } \\
1951\end{array}$ & $\mathrm{~Pb}$ & $\begin{array}{r}62.5 \\
72.1 \\
78.9 \\
82.4 \\
89.1 \\
95.3 \\
104.1 \\
106.6 \\
114.1\end{array}$ & $\begin{array}{l}7.41 \\
9.4 \\
11.01 \\
11.82 \\
13.5 \\
15.15 \\
17.58 \\
18.28 \\
20.7\end{array}$ & $\begin{array}{l}7.375 \\
9.404 \\
10.96 \\
11.8 \\
13.48 \\
15.12 \\
17.57 \\
18.29 \\
20.52\end{array}$ & $\begin{array}{l}0.5 \\
0 \\
0.4 \\
0.1 \\
0.1 \\
0.2 \\
0.1 \\
0 \\
0.9\end{array}$ \\
\hline $\begin{array}{l}\text { Mather } \\
1951\end{array}$ & $\begin{array}{l}\mathrm{Pb} \\
\mathrm{Cu} \\
\mathrm{Al}\end{array}$ & $\begin{array}{l}338.5 \\
339.7 \\
339.7 \\
339.7\end{array}$ & $\begin{array}{r}123.25 \\
124.61 \\
92.69 \\
79.42\end{array}$ & $\begin{array}{c}123.88 \\
124.58 \\
93.65 \\
80.6\end{array}$ & $\begin{array}{c}-0.5 \\
0 \\
-1.0 \\
-1.5\end{array}$ \\
\hline $\begin{array}{l}\text { Vasilevskil } \\
1969\end{array}$ & $\begin{array}{l}\mathrm{Pb} \\
\mathrm{Al}\end{array}$ & $\begin{array}{l}620 \\
620\end{array}$ & $\begin{array}{c}318.2 \\
-\end{array}$ & $\begin{array}{l}313.4 \\
206.1\end{array}$ & $\begin{array}{c}1.5 \\
-\end{array}$ \\
\hline $\begin{array}{l}\text { Barkas } \\
1969\end{array}$ & $\begin{array}{l}\mathrm{Pb} \\
\mathrm{U} \\
\mathrm{Al} \\
\mathrm{Cu}\end{array}$ & $\begin{array}{l}750 \\
750 \\
750 \\
750\end{array}$ & $\begin{array}{c}417.7 \\
434.7 \\
274.7 \\
-\end{array}$ & $\begin{array}{l}413.0 \\
429.2 \\
274.1 \\
316.5\end{array}$ & $\begin{array}{l}1.1 \\
1.3 \\
0.2 \\
-\end{array}$ \\
\hline
\end{tabular}


TABLE XI. Contributions to the stopping number, L, Eqs. (2) for protons of energy $\mathrm{T}(\mathrm{MeV})$ passing through a gold absorber w1th $I=790 \mathrm{eV}$, ln $I=6.672 . \quad L_{B}=f(\beta)-$ ln I. The shell corrections, $c_{1}$ and $C$ are defined in Eq. ( $(9)$, L in Eq. (6), and $L_{2} 1 n^{1} \mathrm{Eq}$. (9). The density effect is included in $f(\beta)$, it amounts to 0.062 at $100 \mathrm{MeV}$. Note that a fractional change of $Y$ in $L$ (or S) causes a change of (YL) in the Ivalue.

\begin{tabular}{cccccccc}
$T$ & $I$ & $L_{B}$ & $f(\beta)$ & $C_{1}$ & $C_{0}$ & $I_{1}$ & \multicolumn{1}{l}{$I_{2}$} \\
0.30 & 0.5374 & -0.1901 & 6.4819 & -0.6270 & 0.0398 & 0.2338 & 0.0935 \\
0.40 & 0.6374 & 0.0974 & 6.7695 & -0.5398 & 0.1252 & 0.1968 & 0.0713 \\
0.50 & 0.7273 & 0.3204 & 6.9924 & -0.4724 & 0.1800 & 0.1721 & 0.0577 \\
0.60 & 0.8097 & 0.5026 & 7.1746 & -0.4175 & 0.2163 & 0.1543 & 0.0484 \\
0.70 & 0.8862 & 0.6565 & 7.3286 & -0.3714 & 0.2408 & 0.1407 & 0.0417 \\
0.80 & 0.9575 & 0.7899 & 7.4619 & -0.3317 & 0.2573 & 0.1299 & 0.0366 \\
0.90 & 1.0245 & 0.9075 & 7.5796 & -0.2969 & 0.2683 & 0.1210 & 0.0326 \\
1.00 & 1.0876 & 1.0127 & 7.6848 & -0.2662 & 0.2755 & 0.1136 & 0.0295 \\
1.10 & 1.1472 & 1.1079 & 7.7799 & -0.2386 & 0.2798 & 0.1073 & 0.0268 \\
1.20 & 1.2037 & 1.1947 & 7.8667 & -0.2138 & 0.2820 & 0.1019 & 0.0246 \\
1.30 & 1.2574 & 1.2746 & 7.9466 & -0.1912 & 0.2828 & 0.0971 & 0.0228 \\
1.40 & 1.3083 & 1.3485 & 8.0206 & -0.1703 & 0.2823 & 0.0929 & 0.0212 \\
1.50 & 1.3573 & 1.4174 & 8.0894 & -0.1515 & 0.2809 & 0.0891 & 0.0198 \\
1.60 & 1.4041 & 1.4817 & 8.1538 & -0.1341 & 0.2790 & 0.0857 & 0.0186 \\
1.70 & 1.4489 & 1.5422 & 8.2142 & -0.1180 & 0.2765 & 0.0827 & 0.0175 \\
1.80 & 1.4920 & 1.5992 & 8.2712 & -0.1031 & 0.2736 & 0.0799 & 0.0165 \\
1.90 & 1.5334 & 1.6531 & 8.3251 & -0.0891 & 0.2705 & 0.0774 & 0.0157 \\
2.00 & 1.5732 & 1.7042 & 8.3763 & -0.0761 & 0.2672 & 0.0750 & 0.0149 \\
2.50 & 1.7533 & 1.9265 & 8.5986 & -0.0221 & 0.2491 & 0.0657 & 0.0120 \\
3.00 & 1.9080 & 2.1080 & 8.7801 & 0.0181 & 0.2309 & 0.0589 & 0.0100 \\
3.50 & 2.0437 & 2.2614 & 8.9334 & 0.0490 & 0.2137 & 0.0537 & 0.0086 \\
4.00 & 2.1648 & 2.3941 & 9.0661 & 0.0733 & 0.1981 & 0.0496 & 0.0075 \\
5.00 & 2.3737 & 2.6156 & 9.2876 & 0.1081 & 0.1712 & 0.0434 & 0.0060 \\
10.00 & 3.0631 & 3.3007 & 9.9727 & 0.1677 & 0.0956 & 0.0288 & 0.0030 \\
30.00 & 4.2076 & 4.3686 & 11.0407 & 0.11441 & 0.0310 & 0.0152 & 0.0010 \\
100.00 & 5.4012 & 5.4819 & 12.1539 & 0.0787 & 0.0095 & 0.0078 & 0.0003
\end{tabular}


Table XII. Stopping power table for protons in several elements as a function of kinetic energy $\mathrm{T}$. Below $1 \mathrm{MeV}$, the uncertainty is several percent; above $1 \mathrm{MeV}$ it is mainly determined by the error in the I-value. If a linear interpolation is made for in $S$ and in $T$, the maximum error of interpolated values is $0.1 \%$.

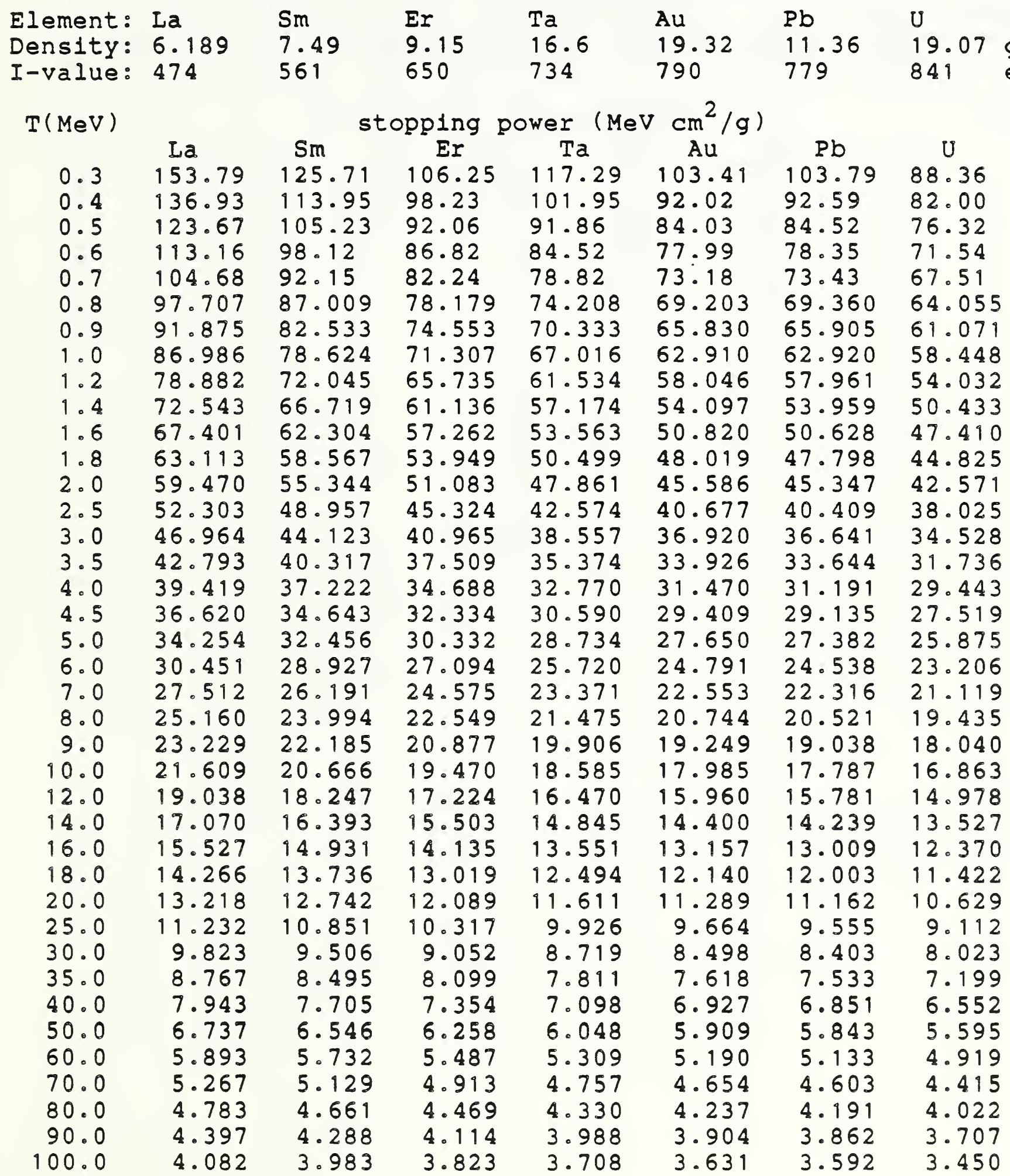


Table XIII. Stopping power table for alphas in several elements as a function of kinetic energy $T$. Below $2 \mathrm{MeV}$, the uncertainty is several percent; above $1 \mathrm{MeV}$ it is mainly determined by the error in the I-value. If a linear interpolation is made for in $S$ and in $T$, the maximum error of interpolated. values is 0.18 .

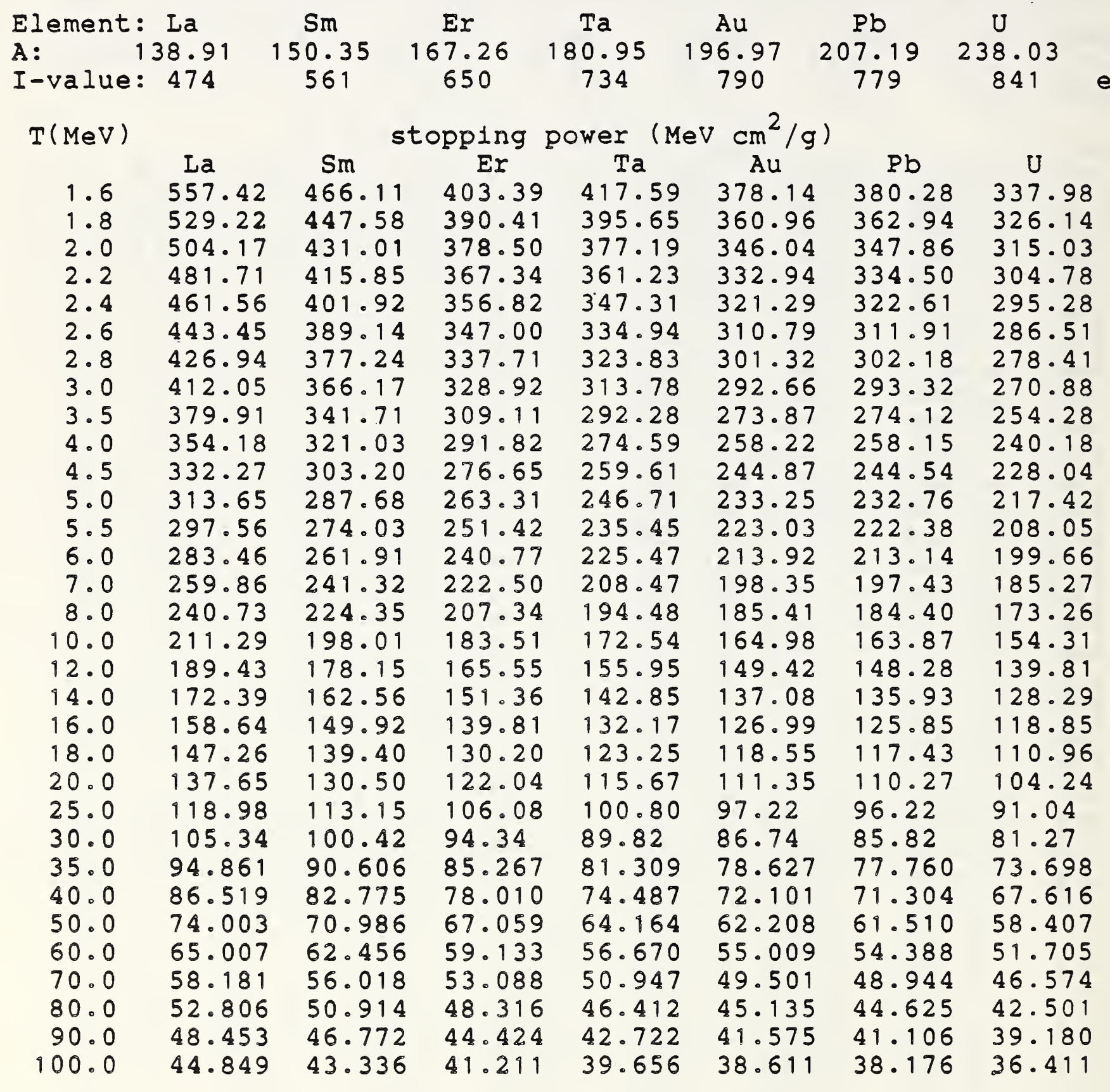




\section{Figure captions}

FIG. 1. Shell corrections, $C_{\nu}$, calculated for gold with the nonrelativistic hydrogenic approximation (K-shell: Walske, 1952; L-shells: Bichsel, 1987; M-shells: Bichsel, 1983). The scaled functions ${ }_{r} C_{\nu}$ are plotted vs. a common, scaled abscissa $\eta$. The scaling was chosen to give the ordinate value 1.0 at the maximum for each function and to have the maximum value at the same value of the abscissa, viz. $\eta=0.18$. The actual function, $C_{\nu}$, can be obtained by using $\eta_{\nu}=f_{\nu} \cdot \eta$, and $C_{\nu}\left(\eta_{\nu}\right)=g_{\nu} \cdot{ }_{r} C_{\nu}(\eta)$, where $f_{\nu}$ and $g_{\nu}$ are given below.

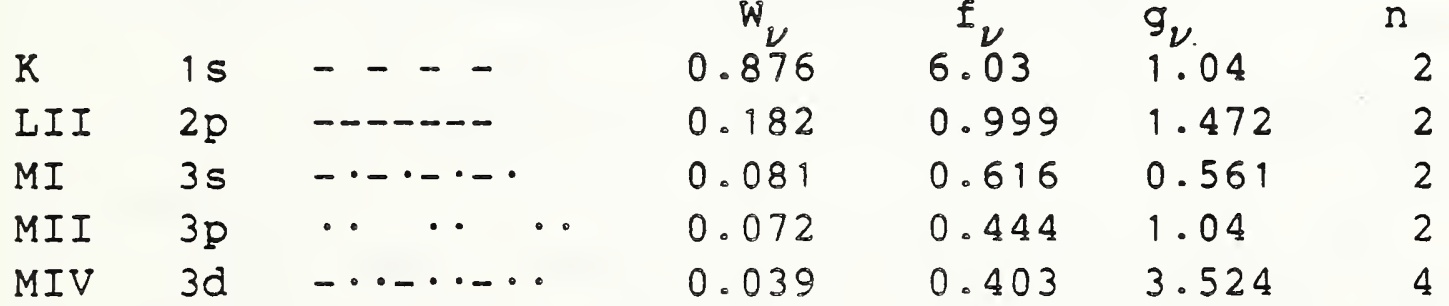

The functions for II, IIII' MIII and $M_{V}$ are not shown ( $I_{I}$ lies very close to $M_{I}$ ). Note that $g_{\nu}$ is not proportional to the number of electrons $n$ in the subshellis, and $f_{\nu}$ is only approximately proportional to $w_{\nu}=J_{\nu} / \epsilon_{\nu}, E q \cdot(4 b)$.

FIG. 2. Total shell corrections $\mathrm{C} / \mathrm{Z}$ for protons with kinetic energy $T$ in gold metal. Solid line: present values; dasheddotted line: calculation by Bonderup (1967), using the LenzJensen model of the atom; dotted line: experimental function used by Andersen and Ziegler (1977); dashed Iine: Janni (1982). Note that in Eq. (2a) an increased shell correction can give approximately the same $L_{0}$ if $I$ is reduced.

FIG. 3. Values of the vertical scaling factor $V_{3}$ for the outermost shelis, for best fits to different experimental data sets for protons, as a function of atomic number $z$ for $z \geq 73$. The parameters $V_{1}=1.25, V_{2}=1.4, H_{3}=13$ were used for all $Z$. Resulting I-values differ for each set (Fig. 5). The function $V_{3}=(z-46) / 25$ is shown as a solid line. It is not possible to assign uncertainties derived from $\sigma_{e}$ to individual values because $V_{3}$ as well as $I$ would change with changes in $\mathrm{s}_{\mathrm{x}}$. Symbols are related to authors in Table $V$. 
EIG. 4. Same as Eig. 3 for $\mathrm{Z} \leq 72$, but data for $\alpha$ with $\mathrm{T} \geq 2 \mathrm{MeV}$ (Er, $Z=68$, Oberlin and Langley) were also included. The following parameters were used: $v_{1}=1.25, v_{2}=1.4$ for all $Z$; $\mathrm{H}_{3}=50$ for $\mathrm{Z}<60, \mathrm{H}_{3}=25$ for $\mathrm{Z}>60$ (Table VI). Resulting I-values differ for each set of experimental data. No systematic dependence of $V_{3}$ on $z$ is evident, thus $V_{3}=3.85$ was chosen as an approximate average for $z \leq 60, v_{3}=2.3$ for $Z>60$. For symbols, see Table $V$.

FIG. 5. Values of the Bloch parameter $b_{a}=I_{a} / Z$ for different experimental data sets for protons and $\alpha$ as a function of atomic number $z$, with $V_{1}=1.25, v_{2}=1.4$ for all $z$, the other parameters given as a function of $\mathrm{Z}$ : for $\mathrm{Z}<60, \mathrm{H}_{3}=50, \mathrm{~V}_{3}=3.85$; for $60<\mathrm{Z} \leq 72: \quad \mathrm{H}_{3}=25, \mathrm{~V}_{3}=2.3$, and for $\mathrm{Z}>72: \quad \mathrm{H}_{3}=13, \mathrm{~V}_{3}=(\mathrm{Z}-$ 46)/25. The different ${ }^{3}$ values $b_{a}$ at each $z$ express the systematic differences in the experimental data (Table VIa). An uncertainty of $\pm 1 \%$ in $S_{x}$ gives an uncertainty of about $\pm 1 \%$ in $\mathrm{b}_{\mathrm{a}}$ at $1 \mathrm{MeV}$, about $\pm 3 \%$ at $10 \mathrm{MeV}$ (Table X). The unweighted mean value for $p=18$ measurements in gold is $I=(788 \pm 12)$ ev, for Pb, $p=8, I=(779 \pm 25) \mathrm{eV}$.

FIG. 6. Comparison of experimental and theoretical values of the proton and deuteron stopping power for gold. In order to show differences clearly, the relative difference, $r(T)$ (Eq. (11)) is given as a function of the kinetic energy per nucleon, $T / M$ of the particles. The theoretical values were calculated with $V_{1}=1.25, V_{2}=1.4, H_{3}=13, V_{3}=(Z-46) / 25=1.32$, and $I_{e}=789.9 \mathrm{eV}$. Some data are not shown here, but are included in Fig. 6a. Symbols are given in Table $v$ i continuous ines are used for smoothed data: dashed-double dotted: Bader et 21. (1956); double-dotted: Green et al. (1955); dashed: Luomajurv1 (1979); dashed-dotted: S申rensen and Andersen (1973); solid line above $0.8 \mathrm{MeV}:$ Andersen and Nielsen (1981). The $\alpha$ and I1 data by Andersen et al. (1977) between $i$ and $4 \mathrm{MeV} / \mathrm{M}$ are shown by dotted lines. For the data by semrad (1990) below $0.8 \mathrm{MeV}$, a smooth solid line is shown. It differs on the average by less than $\pm 0.7 \%$ from $S_{X^{\prime}}$ with $a$ maximum difference of $\pm 1.2 \%$ (see Fig. $6 a$ ). The data by Green et al. and by Bader et al. were not included in the data adjustment of section III. Thus their deviation is relatively large. Experimental uncertainties, $\sigma_{e^{\prime}}$ given by the authors 
are shown for only a few values. Negative values of $r$ imply values of $I_{x}$ less than $I_{e}$.

FIG. 6a. Comparison of experimental and theoretical values of the stopping power for gold for energies per nucleon, $T / M$, between 0.3 and $3 \mathrm{MeV}$. Symbols are given in Table $V$. Individual values of the data by semrad (1990) are shown. $\alpha$ data by Fontell and Luomajurvi (1979) are shown as the dashdotted line, those by Matteson et al. (1978) as a solid line between 0.35 and $0.55 \mathrm{MeV} / \mathrm{u}$, for other data see Fig. 6 . $\alpha$ data by Iin et al. (1974) differ by less than 1 f from those of Fontell and Luomajarvi and are not shown.

For the Luomojurvi and the Andersen-Nielsen data, similar systematic deviations of about $\pm 0.5 \%$ of $r(T)$ are seen between 0.8 and $1.5 \mathrm{MeV}$. There may be a problem in the theory or in the experiments or both in this region. The increase in $r(T)$ for $\alpha$ below $\mathrm{T} / \mathrm{M}=0.5 \mathrm{MeV}$ may be due to a reduced charge $z$ of the particles.

FIG. 7. Comparison of experimental and theoretical values of the stopping power for tantalum. The relative difference, $r(T)$ in 8 (Eq. (11)), is given as a function of particle energy per nucleon, $T / M$. The theoretical values were calculated with $\mathrm{H}_{3}=13, \mathrm{~V}_{3}=1.08$, and $\mathrm{I}_{\mathrm{e}}=734 \mathrm{eV}$. Symbols are given in Table $V$. Experimental error bars are given at only a few values. Continuous lines show data smoothed by the authors. The proton data by Bader et al. (1956) below 0.6 $\mathrm{MeV}$ are shown as the dotted line; those of sorensen and Andersen (1973) above $2.25 \mathrm{MeV}$ as a solid line. The dashed Ine shows the proton data by Luomajurvi (1979). $\alpha$-data by Iin et al. (1973) are shown by the solid line ending at 8.5\%. For $2 \mathrm{MeV} \alpha, r=(2.9 \pm 3)$ for Chu et al. (1973).

The difference in $r$ between the Luomojurvi and the Andersen data at neighbouring energies $(1.5$ and $2.25 \mathrm{MeV})$ is about $3 \%$, thus equal to the sum of the experimental errors $\sigma_{e}$. I consider it unlikely that.this is a problem in the theory.

FIG. 8. Comparison of experimental and theoretical values of the stopping power for lead. The relative difference, $r(T)$, (Eq. (11)) is given as a function of $T / M$. The theoretical values were calculated with $\mathrm{H}_{3}=13, V_{3}=1.44$, and $I_{e}=779 \mathrm{eV}$. 
For individual data points, see symbols in Table $v$. Values of $r$ for the data by Bader et al. (1956), dashed line, and Green et al. (1955), dotted line, show similar deviation as those for gold. The data by Shrensen and Andersen (1973) are shown by the solid line. The $\alpha$-data by Borders (1974) for $1.2 \leq \mathrm{T}(\mathrm{MeV}) \leq 1.8$ are shown by the solid line.

FIG. 9. Comparison of experimental and theoretical stopping power values for $\mathrm{La}, \mathrm{Ce}$ and $\mathrm{Pr} . \mathrm{S}_{t}$ was calculated with the parameters $\mathrm{H}_{3}=50, V_{3}=3.85$. The I-values $I_{e} \mathrm{~b}_{\mathrm{e}} \cdot \mathrm{Z}$ (eV) (Table I) are shown next to the chemical symbol. "Symbols are shown in Table $v$. The solid lines represent the $\alpha$-data by Knudsen et al. (1980), the dotted line for La those by Lin et al. (1973).

FIG. 10. Comparison of experimental and theoretical stopping power values for $\mathrm{Sm}, \mathrm{Gd}$ and Dy. $S_{t}$ is calculated with the parameters $\mathrm{H}_{3}=25, V_{3}=2.3$, and $I_{e}=b \cdot b_{e} Z$ of Table $I$. Symbols are defined in Table $v$. Note that Sirotinin et al. (1984) for Sm and $\mathrm{Gd}$ gave two values of $\mathrm{S}_{\mathrm{x}}$ at $0.3,0.4,0.8$ and $1 \mathrm{MeV}$. Both values are shown. For Gd, the dashed line represents the proton data given by Andersen et al. (1967), the dotted line the $\alpha$ data by oberlin et al. (1980). The solid lines show the $\alpha$-data by knudsen et al. (1980), the dotted line for DY those by lin et al. (1973).

FIG. 19. Comparison of experimental and theoretical stopping power values for HO, Er and $Y b . S_{t}$ is calculated with the parameters $\mathrm{H}_{3}=25, V_{3}=2.3$, and $I_{e}=b e^{\cdot Z}$ of Table $I$. Symbols are defined in Table $v$. The solid lines show the $\alpha$-data by Knudsen et al. (1980). For Er, data by Oberlin et al. (1982) are shown as smoothed lines which were obtained by making a three parameter fit $\left(\mathrm{H}_{3}, \mathrm{~V}_{3}\right.$, I) to their experimental data; $\mathrm{p}$ : dotted line, $\alpha$ : dashed line. The Langley and Blewer (1976) data for Er are shown by the squares: empty for protons, full for $\alpha$.

FIG. 12. Comparison of experimental and theoretical stopping power values for $\mathrm{Hf}\left(\mathrm{H}_{3}=25, \mathrm{~V}_{3}=2.3\right), \mathrm{W}$ and Ir $\left(\mathrm{H}_{3}=13, \mathrm{~V}_{3}=(\mathrm{Z}-\right.$ 46)/25). S $S_{t}$ is calculated with $I_{e}$ of Table I. For $w_{1}$ the dotted line represents the $\alpha$-data by Lin et al. (1973), the dashed-dotted line those by Borders (1974), the dashed line the proton data by Luomajarvi (1979), and the solid line those by Chumanov et al. (1979). UCLA data are given for $W$ and Ir 
at 20 and $30 \mathrm{MeV}$. For $2 \mathrm{MeV} \alpha$, the data by Chu et al.(1973) are plotted as a star at $0.5 \mathrm{MeV}$.

FIG. 13. Comparison of experimental and theoretical stopping power values for $P t, B 1$ and $U$. $S_{t}$ is calculated with the parameters $\mathrm{H}_{3}=13, \mathrm{~V}_{3}=(\mathrm{Z}-46) / 25$ and $\mathrm{I}_{e}$ of Table $\mathrm{I}$. References to the symbols are given in Table $V$. The proton data for $U$ by sorensen and Andersen (1973) are shown by the solid line between 2.25 and $18 \mathrm{MeV}$, as are those for Pt by Andersen et al. (1967). For protons in B1, the data by Green et al. (1955) are shown by the solid line, those by knudsen et al. (1980) by the dashed-double dotted line, the $\alpha$-data by Kuldeep and Jain (1985) are shown by the dotted line, those by Borders (1974) by the dashed line and those by Knudsen et al. (1980) by the dasehd-dotted line. For $2 \mathrm{MeV} \alpha$, the value for $P t$ by Chu et al.(1973) is plotted as a star at $0.5 \mathrm{Mev} / \mathrm{u}$.

FIG. 14. Comparison between present calculations and some other tabulations. The relative difference $r$ is plotted as a function of proton energy $T$, for four elements. The solid Iine represents the function given by Janni (1982), the dashed line that by Andersen and Ziegler (1977), the dotted line that of Williamson et al (1966). 



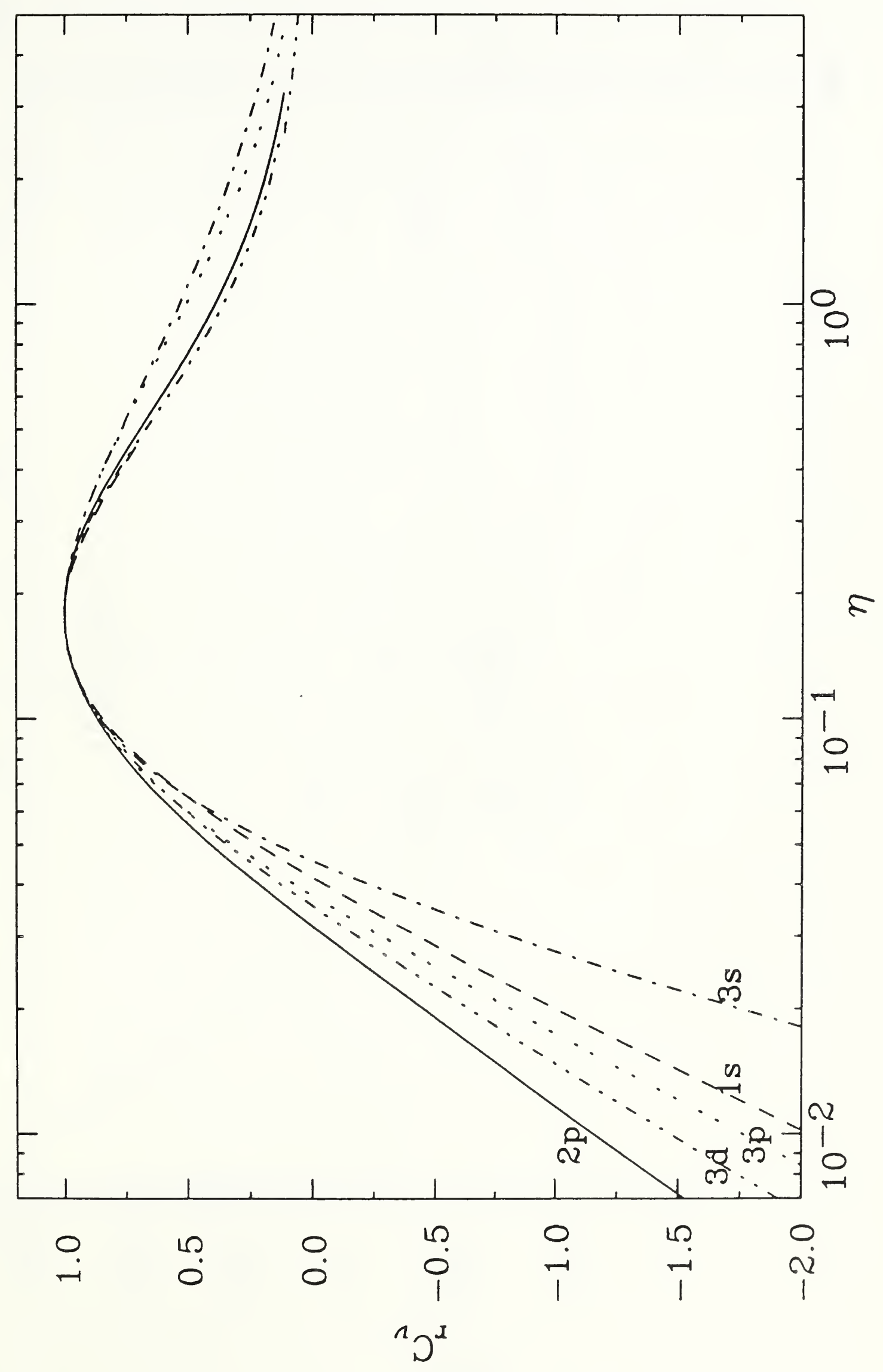




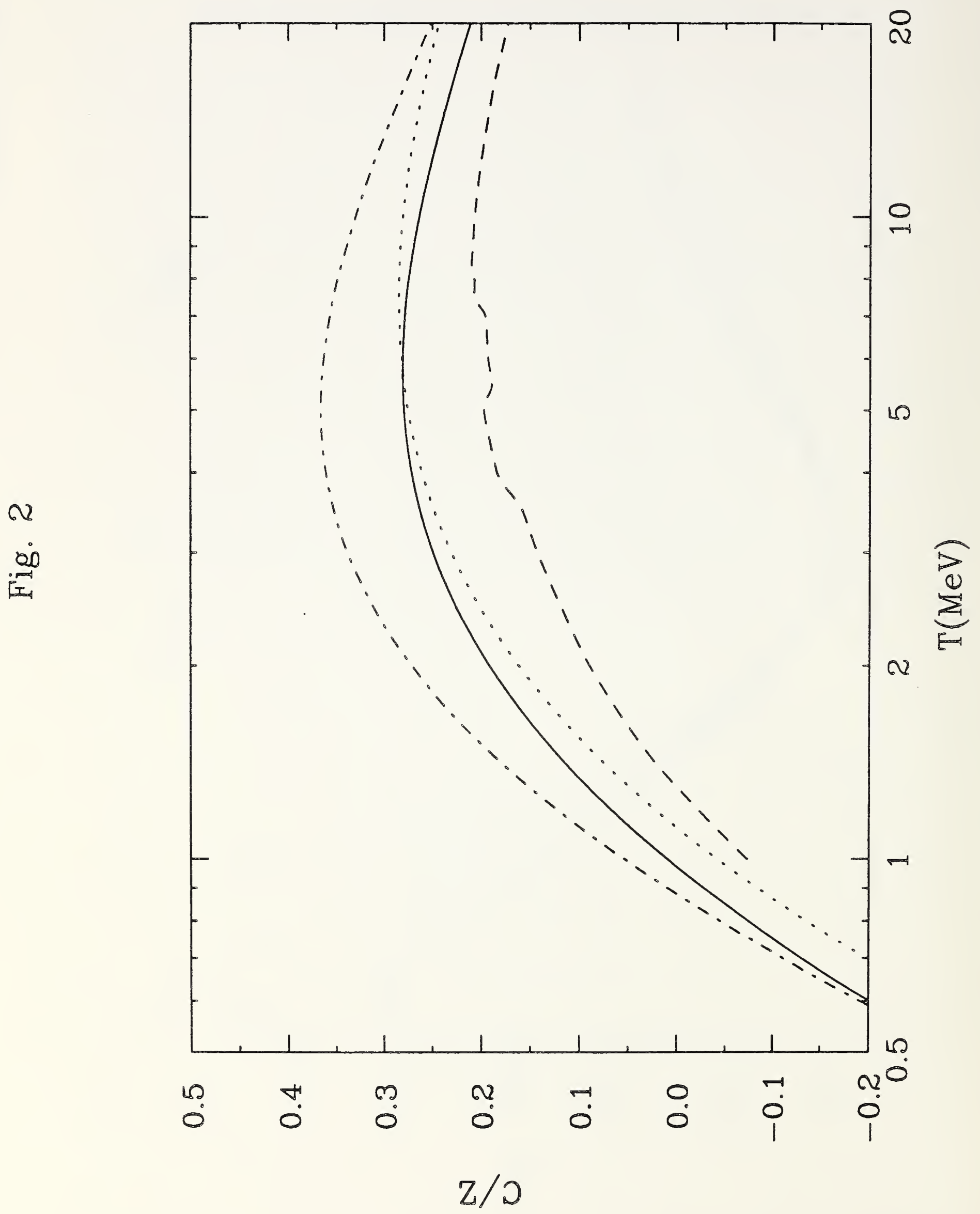




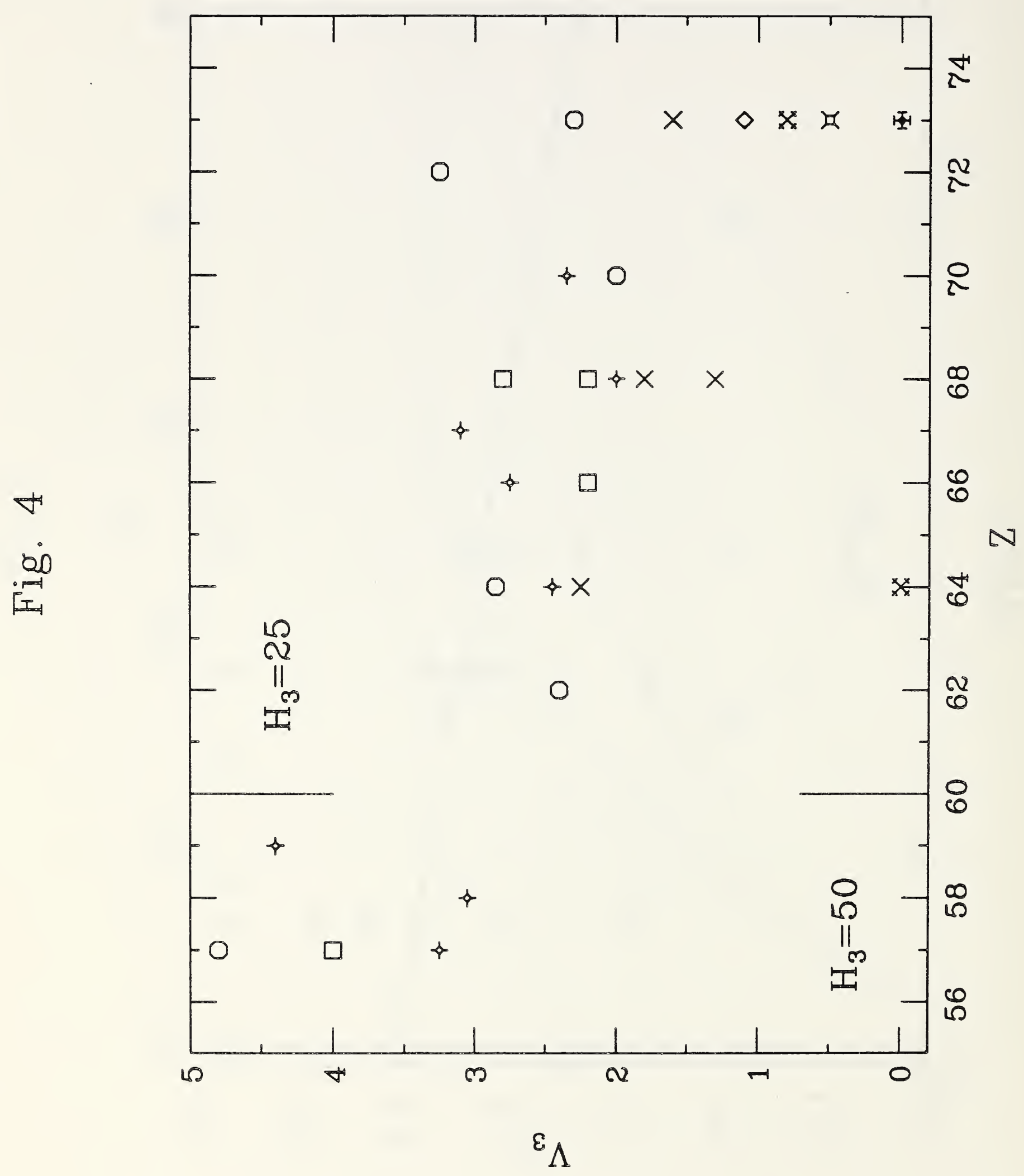




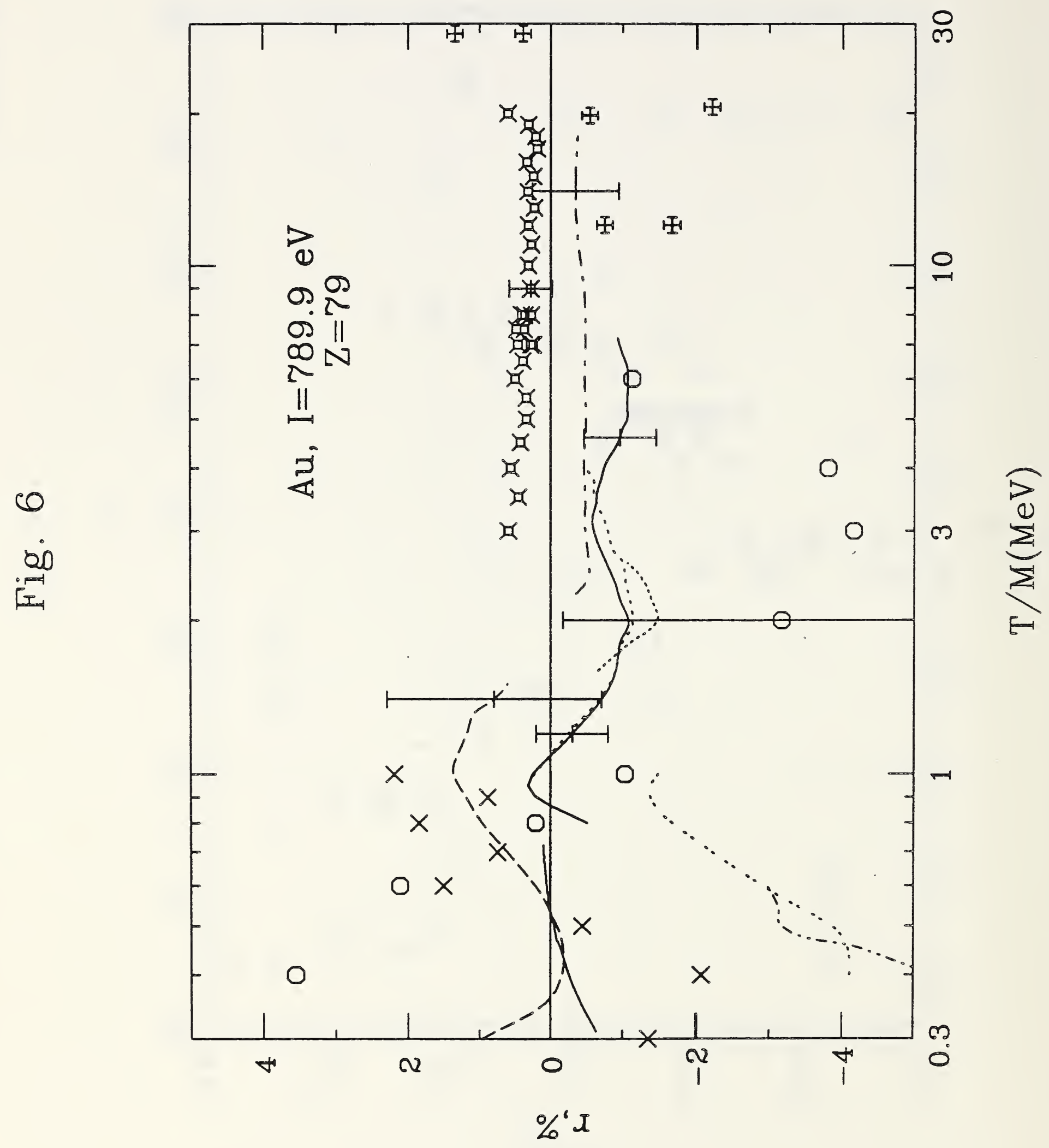




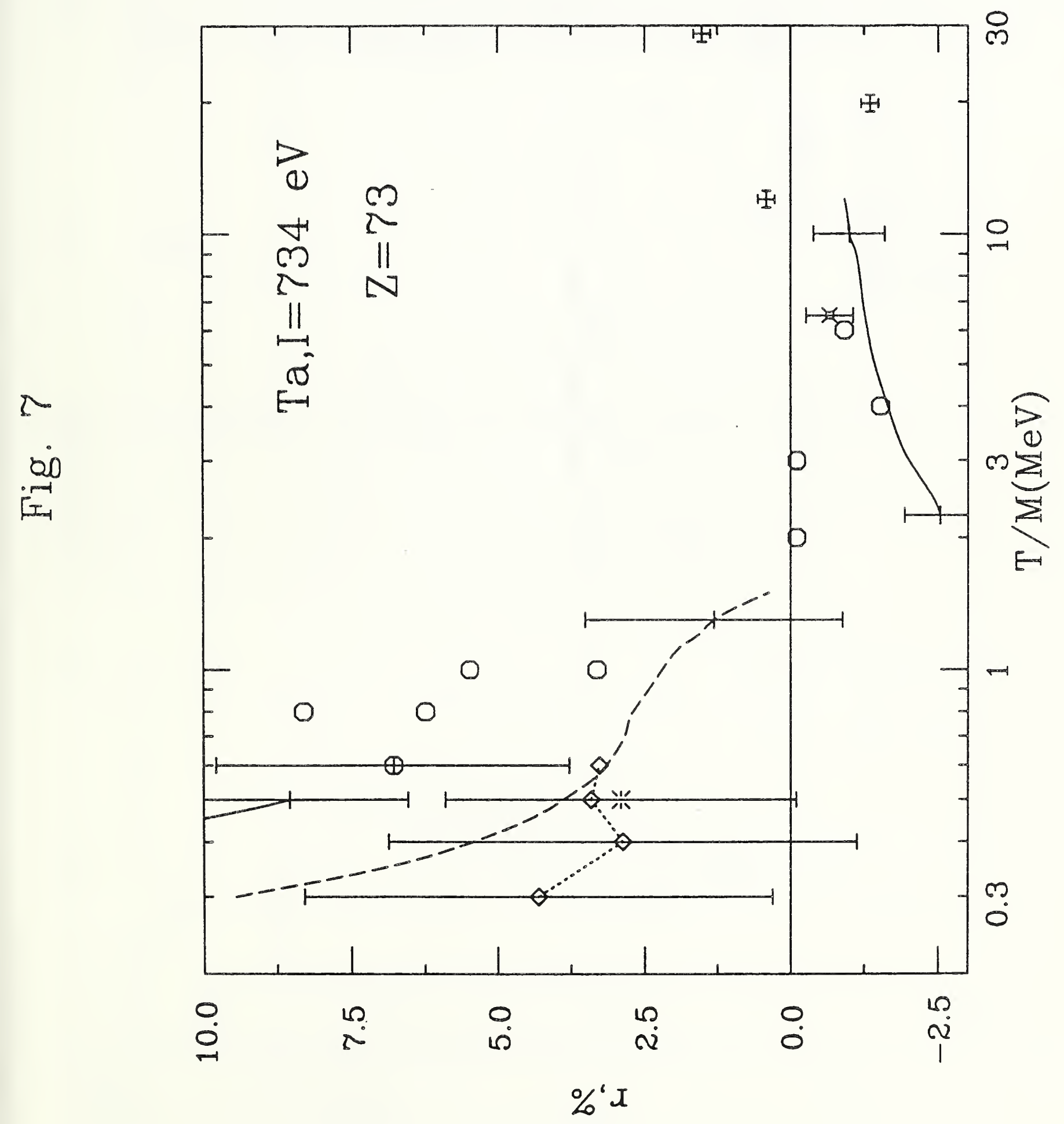




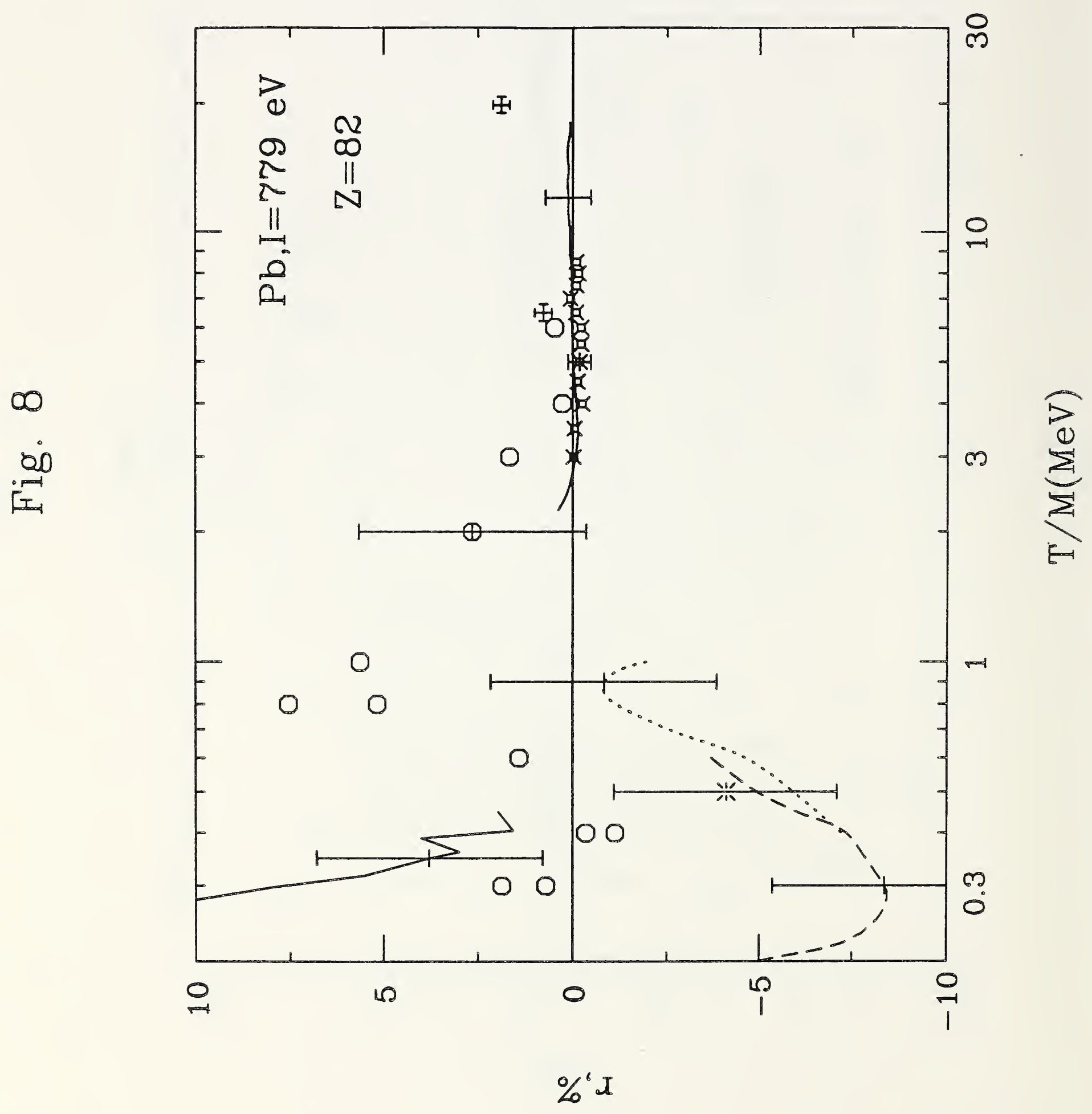


Fig. 9
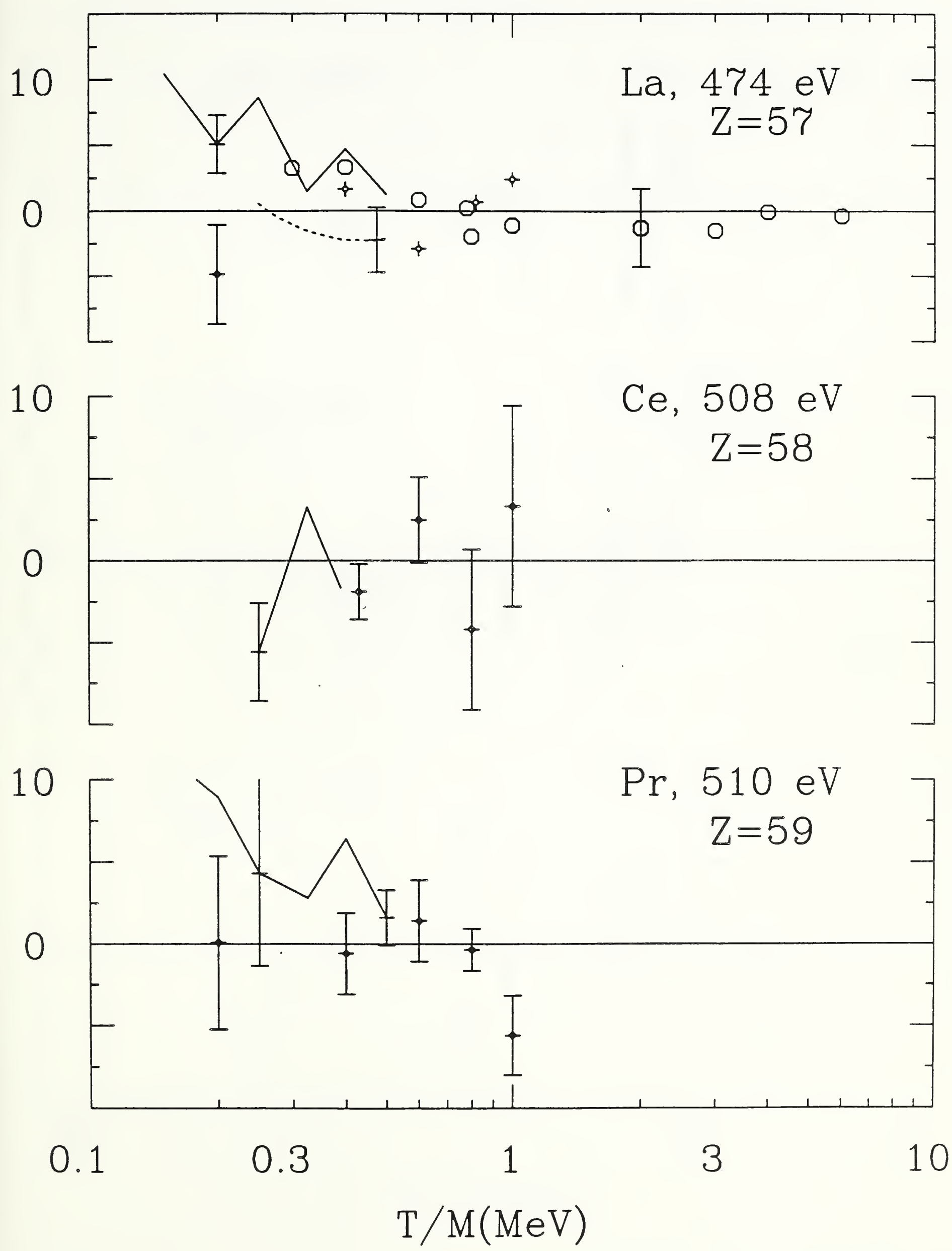

Bichsel, 15. Sep. 1990 
Fig. 10

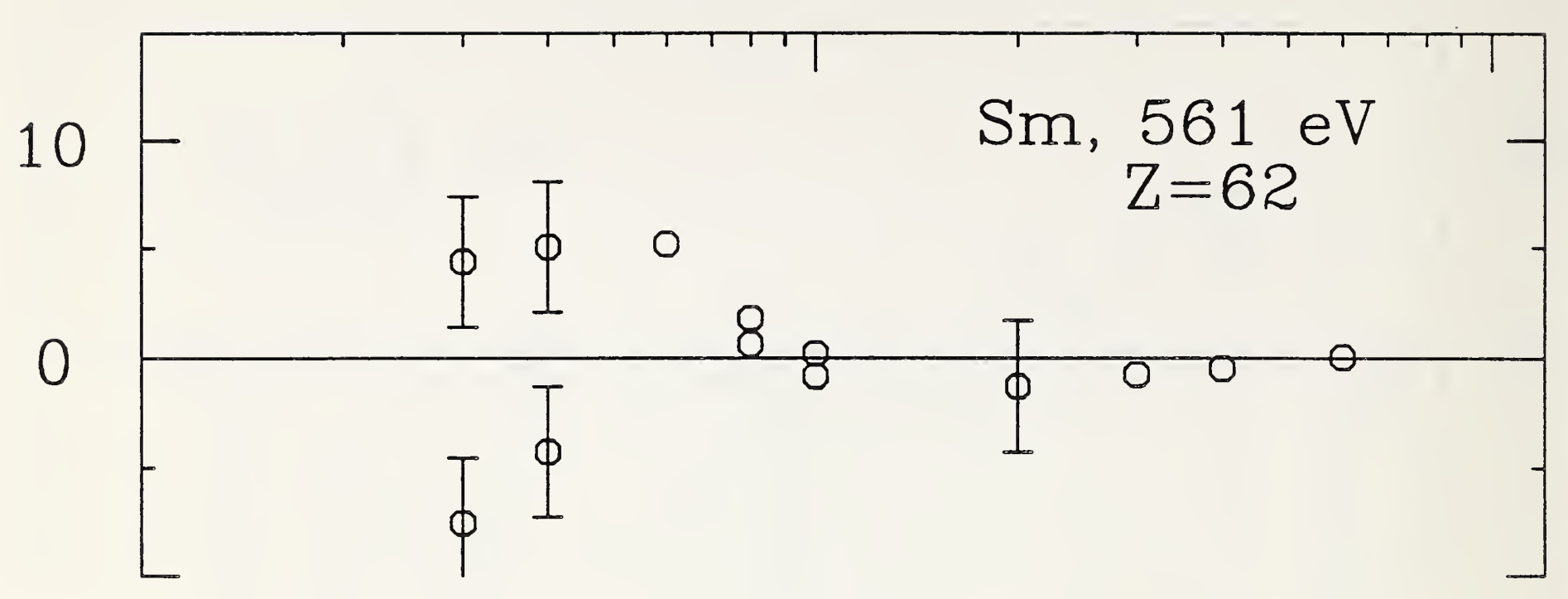

L'

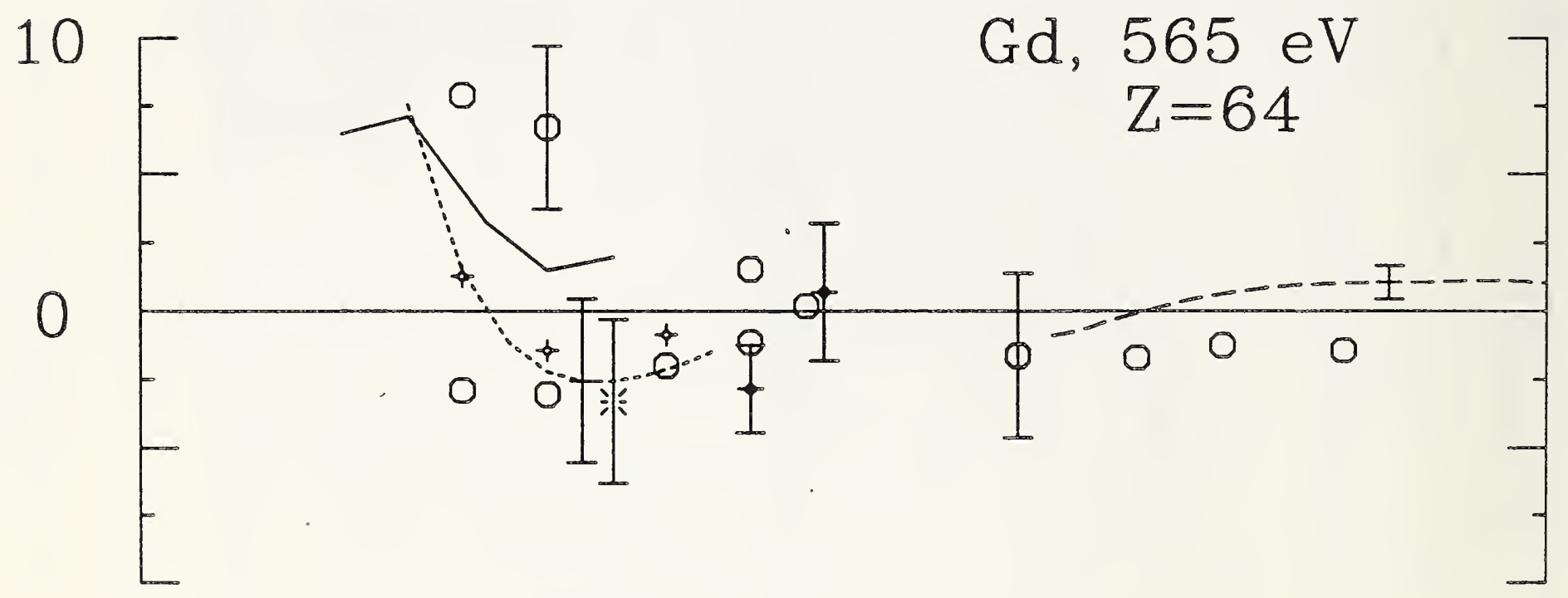

10
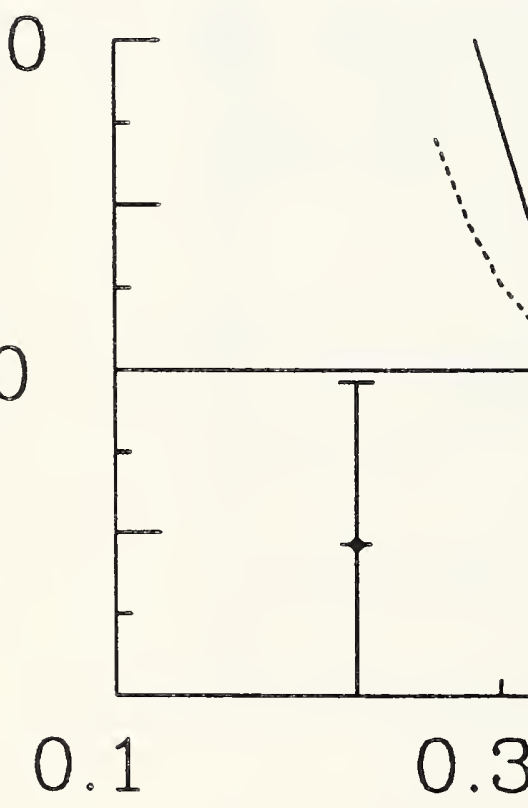

Dy, $\begin{gathered}605 \mathrm{eV} \\ \mathrm{Z}=66\end{gathered}$

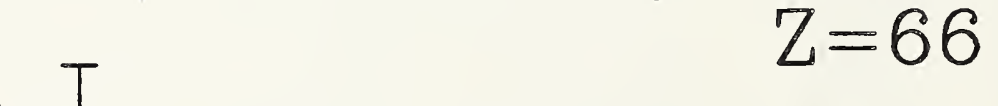


Fig. 11
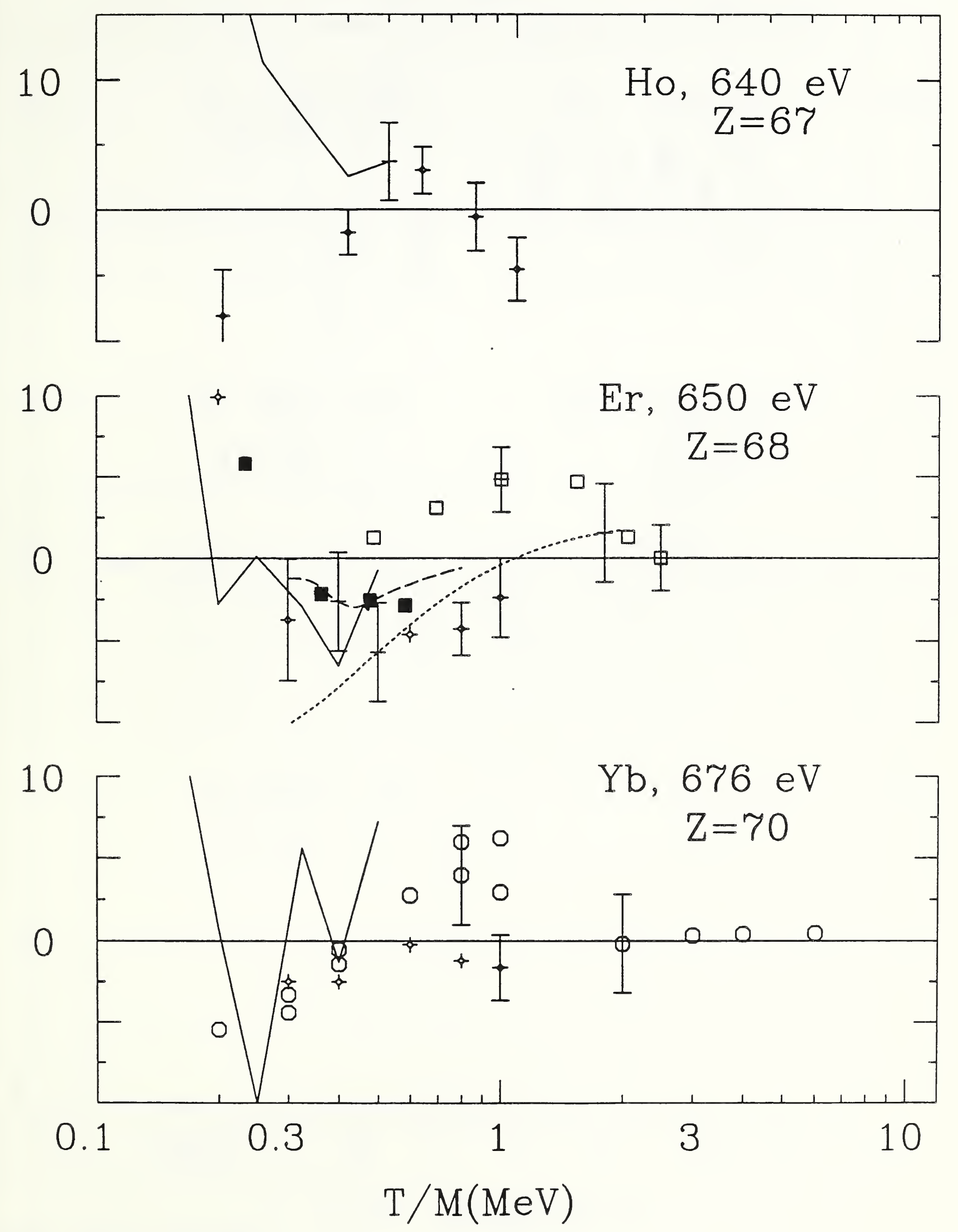

Bichsel, 15. Sep.1990 
Fig. 12
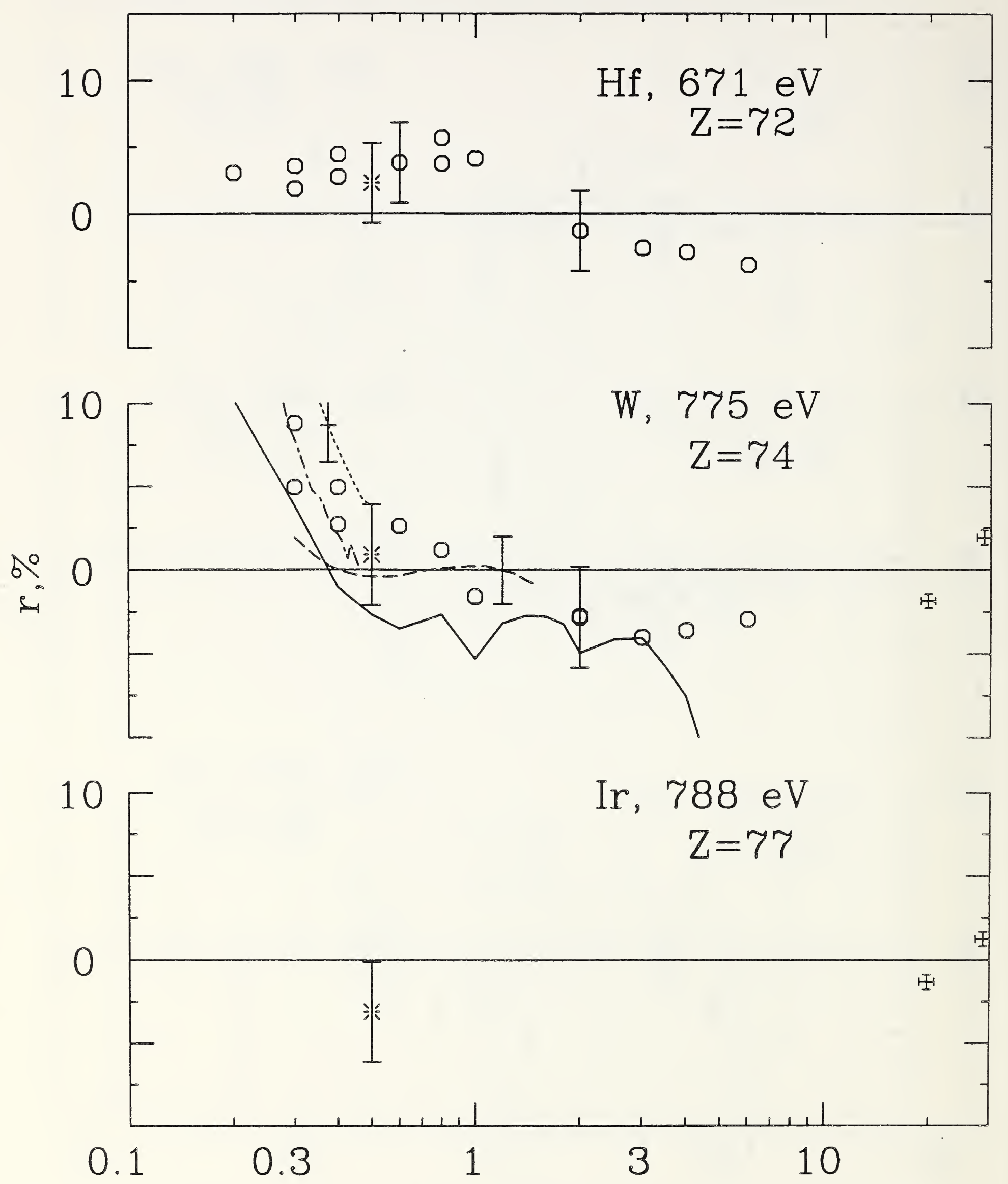

$\mathrm{T} / \mathrm{M}(\mathrm{MeV})$ 
Fig. 13

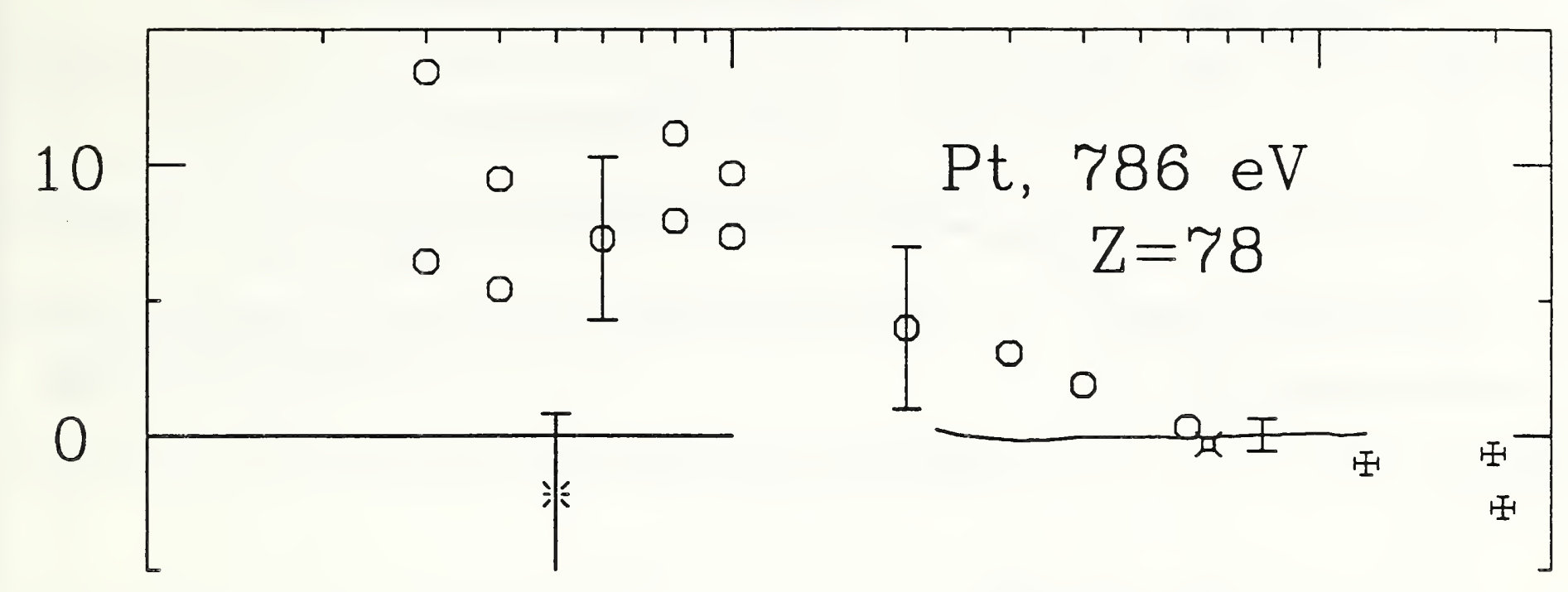

10

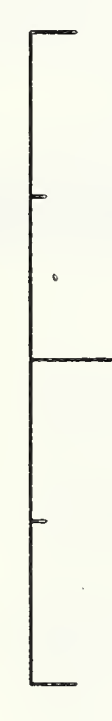

2

2
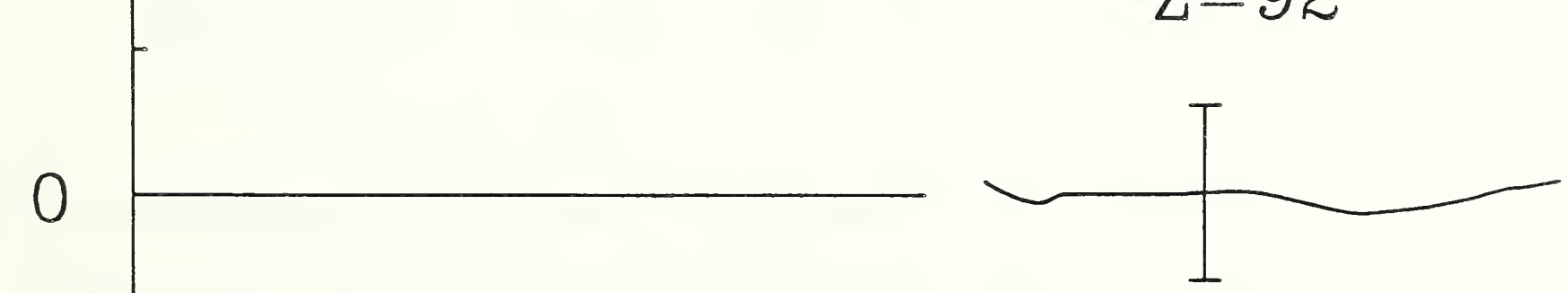

$\mathrm{U}, 841 \mathrm{eV}$

$Z=92$

$\mathrm{Bi}, 745 \mathrm{eV}$

$$
\mathrm{Z}=83
$$

0 
Fig. 14
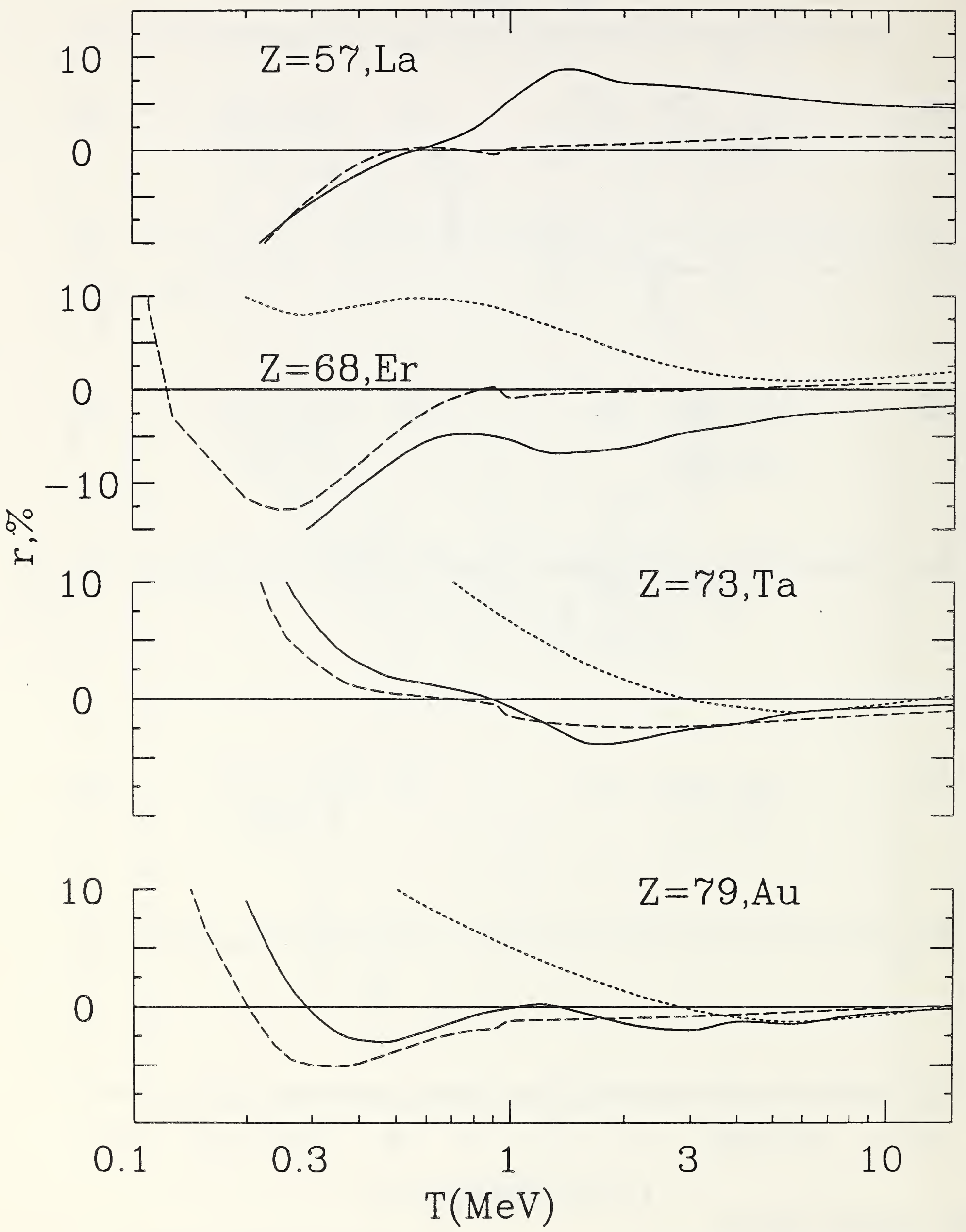

Bichsel, 15. Sept. 1990 


\begin{tabular}{|c|c|c|}
\hline \multirow[t]{4}{*}{$\begin{array}{l}\text { NIST-114A } \\
\text { (REV. 3-89) }\end{array}$} & \multirow{4}{*}{$\begin{array}{l}\text { U.S. DEPARTMENT OF COMMERCE } \\
\text { NATIONAL INSTITUTE OF STANDARDS AND TECHNOLOGY } \\
\text { BIBLIOGRAPHIC DATA SHEET }\end{array}$} & $\begin{array}{c}\text { 1. PUBLCATION OR REPORT NUMBER } \\
\text { NISTIR } 4550\end{array}$ \\
\hline & & \begin{tabular}{|ll}
2 & PERFORMING ORGANIZATION REPORT NUMBER
\end{tabular} \\
\hline & & \\
\hline & & APRIL 1991 \\
\hline
\end{tabular}

4. TITLEAND SUBTITLE

Stopping Power of Fast Charged Particles in Heavy Elements

5. AUTHOA(S)

Hans Bichse1

6. PERFORMING ORGAMIZATION (IF JOINT OR OTHER THAN NIST, SEE INSTRUCTIONS)

U.S. DEPARTMENT OF COMMERCE

MATIONAL INSTITUTE OF STANDARDS AND TECHMOLOGY

GAITHERSBURQ, MD 20899

7. CONTRACT/GRANT NUMBER

8. TYPE OF REPORT AND PERIOD COVERED

9. SPONSORING ORGANIZATION NAME AND COMPLETE ADDRESS (STAEET, CITY, STATE, ZIP)

10. SUPPLEMENTARY NOTES

DOCUMENT DESCRIBES A COMPUTER PROGRAM; SF-185, FIPS SOFTWARE SUMMARY, IS ATTACHED.

11. ABSTRACT (A 200-WORD OA LESS FACTUAL SUMMARY OF MOST SIGMIFICANT INFOAMATION. IF DOCUMENT INCLUDES A SIGMIFICANT BIBULOGRAPHY OA LITERATURE SURVEY, MENTION IT HERE.)

The stopping power formula from Bethe's theory contains terms which are known only approximately and must be estimated with the use of experimental data. These terms include a material constant, the mean excitation energy of the medium, and the shell-, Bloch-and Barkas-corrections. In an analysis of measured proton and alpha-particle stopping powers and ranges, modifying parameters have been introduced into these corrections, and the mean excitation energy was simultaneously adjusted, so as to get the closest possible agreement with experimental results. Such an analysis is reported here for elements with atomic numbers $Z \geq 57$. The modification parameters introduced for the shell corrections have a simple relation to atomic energy levels. The Bethe theory with the adopted mean excitation energies and proposed adjustments of the shell- and Barkas-corrections predicts stopping powers that are in close agreement with experimental values, within the experimental uncertainties. This agreement was obtained for protons with kinetic energies above about $0.5 \mathrm{MeV}$, and for heavier ions of charge $z$ at energies above $(z-1.5) \mathrm{MeV} / \mathrm{u}$.

12. KEY WORDS (6 TO 12 ENTRIES; ALPHABETICAL ORDER; CAPITALLE ONLY PROPER MAMES; AND SEPARATE KEY WORDS BY SEMICOLONS)

Bethe theory; charged particles; heavy elements; mean excitation energies; protons; shell corrections; stopping power$$
\text { (1) }
$$

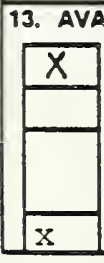

uMUITED

FOR OFFICIAL DISTRIBUTION. DO NOT RELEASE TO NATIONAL TECHNICAL INFORMATION SERVICE (NTIS).

ORDER FROM SUPERINTENDENT OF DOCUMENTS, U.S. GOVERNMENT PRINTING OFFICE, WASHINGTON, DC 20402.

ORDER FROM NATIONAL TECHNICAL INFORMATION SERVICE (NTIS), SPRINGFIELD, VA 22161.

14. NUMBER OF PRINTED PAGES

73

15. PRICE

A04 

$-$ 
